\title{
THE ECONOMIC IMPACT IN STANISLAUS AND SAN JOAQUIN COUNTIES IF A FRUIT AND VEGETABLE PROCESSOR LEFT AS A RESULT OF CHANGES IN THE FOOD PROCESSING BYPRODUCT USE PROGRAM
}

\author{
A Thesis Presented to \\ the Faculty of California Polytechnic \\ State University, San Luis Obispo \\ In Partial Fulfillment of the Requirements for the \\ Degree of Master of Science in Agribusiness
}

By

Jessica Erin Bylsma

December 2009 
(C) 2009

Jessica Erin Bylsma

ALL RIGHTS RESERVED 


\section{APPROVAL PAGE}

TITLE:

AUTHOR:

DATE SUBMITTED:

COMMITEE CHAIR: $\quad$ Dr. Sean Hurley, Associate Professor of Agribusiness

COMMITTEE MEMBER: Dr. Lynn Hamilton, Professor of Agribusiness

COMMITTEE MEMBER: Dr. Hany Khalil, Professor of Food Science and

The Economic Impact in Stanislaus and San Joaquin Counties if a Fruit and Vegetable Processor Left as a Result of Changes in the Food Processing Byproduct Use Program

Jessica Erin Bylsma

December 2009 Nutrition 


\begin{abstract}
Jessica Erin Bylsma

The Economic Impact in Stanislaus and San Joaquin Counties if a Fruit and Vegetable Processor Left as a Result of Changes in the Food Processing Byproduct Use Program

In 1978, Stanislaus County took a proactive approach to food processing byproduct waste and established the Food Processing Byproduct Use Program. It allows processors to transport byproduct to local producers, where it serves as an alternative input. There is concern that the program negatively impacts local groundwater. The Regional Water Quality Control Board proposed that the County institute water monitoring which would increase program expenses. In response to this proposal, participants investigated the impact of the cost increase and some have concluded that this increase would preclude their continued involvement. They believe the program has allowed them to maintain their competitiveness and has kept them from relocating.

This study investigates the economic impact of the food processors leaving the region due to a modification of the current program. Four economic impacts were studied-output, value-added, taxes, and employment. A sensitivity analysis was run to establish a range of possible value and the analysis yielded significantly higher results.

It was estimated that program modification would result in significant fiscal and employment effects for Stanislaus and San Joaquin Counties. This study determined that both Stanislaus and San Joaquin Counties have a vested interest in ensuring that the program remains viable for processors.
\end{abstract}

Key Words: food processing industry, input-output modeling, IMPLAN 
TABLE OF CONTENTS

Pages

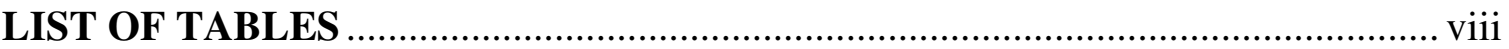

\section{CHAPTER}

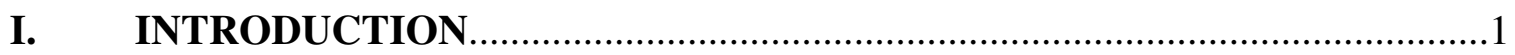

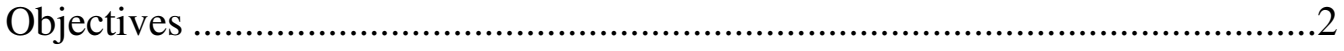

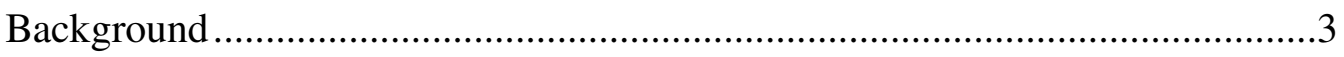

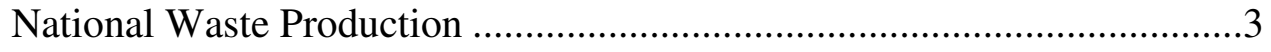

National Recycling Rates ......................................................................

California Waste and Recycling.............................................................

California Solid Waste Bill .......................................................................5

California Food Processing ....................................................................

Food Processing Byproduct Use Program .................................................

Organization of the Thesis ...........................................................................10

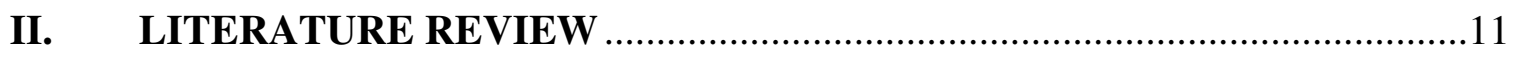

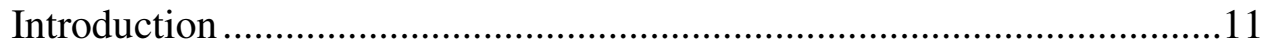

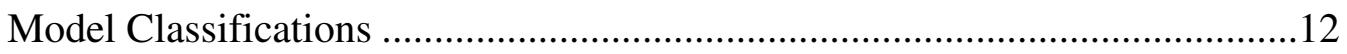

Structural vs. Nonstructural Models ......................................................12

Fixed-Price vs. Price Endogenous Models...................................................12

Regional Economic Models .............................................................................14

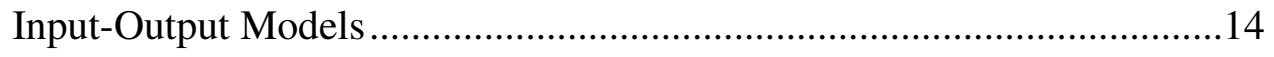

Types of Input-Output Models …………………………………....15 
Alternative Technology Assumptions

Advantages of Input-Output Models .............................................20

Disadvantages of Input-Output Models......................................21

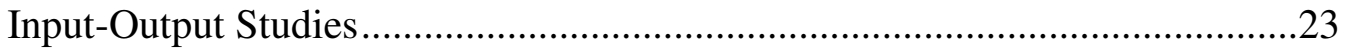

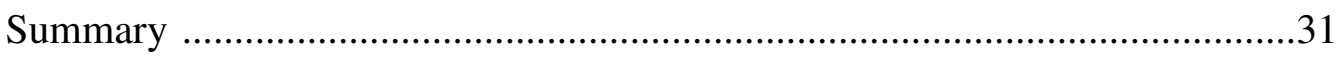

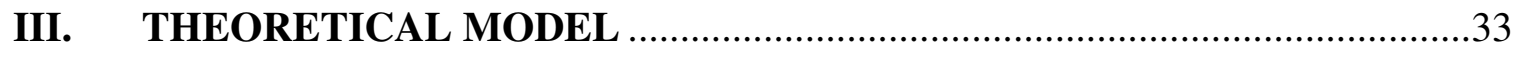

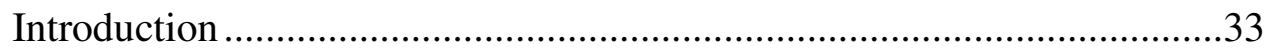

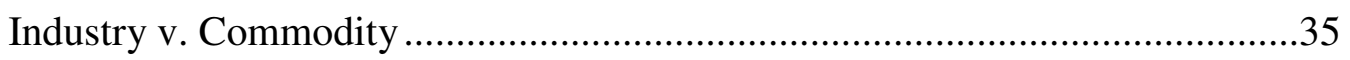

Key Assumptions of Input-Output Modeling .............................................35

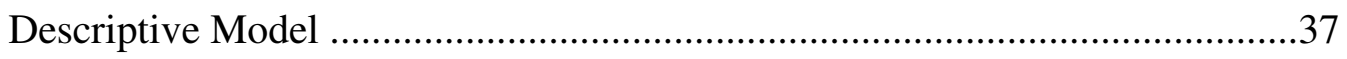

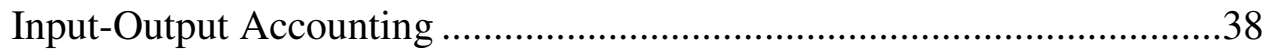

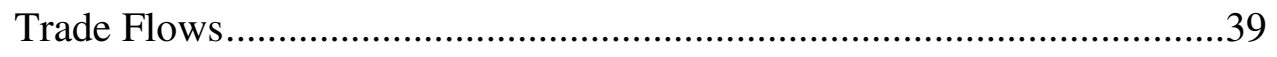

Regional Purchase Coefficients.................................................40

Social Accounting Data................................................................. 40

Predictive Model .............................................................................4

Direct, Indirect, and Induced Effects ................................................4

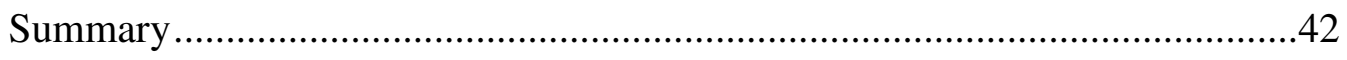

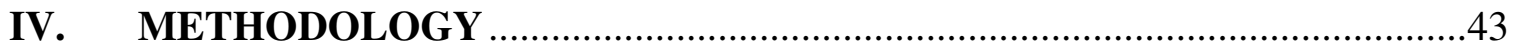

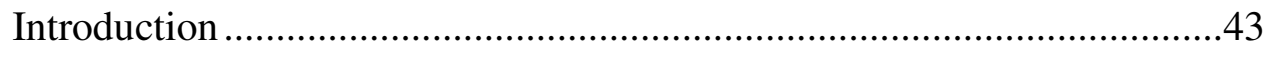

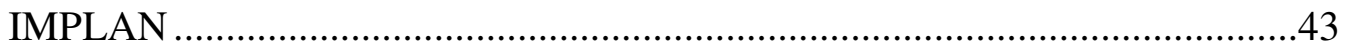

IMPLAN Data ..........................................................................44

Primary Data Collection ................................................................. 45

Scenarios Examined Using IMPLAN ....................................................46 


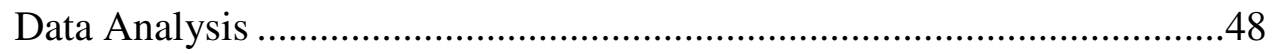

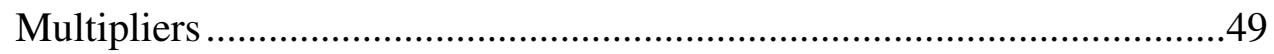

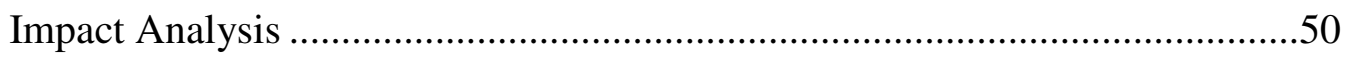

Sensitivity Analysis ...................................................................51

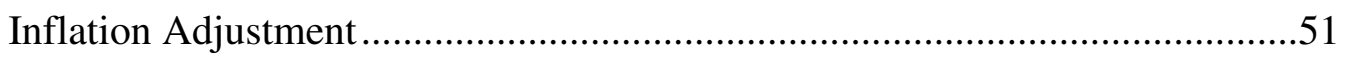

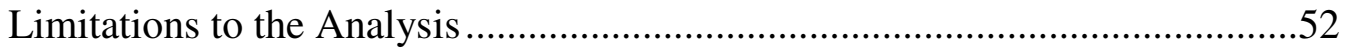

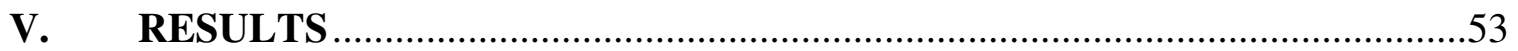

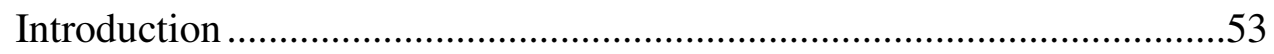

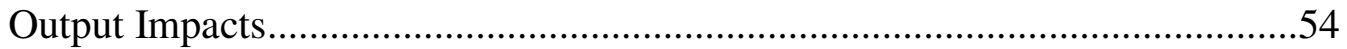

Output Sensitivity Analysis...............................................................56

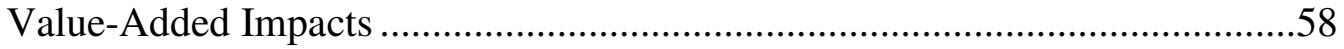

Value-Added Sensitivity Analysis ...................................................60

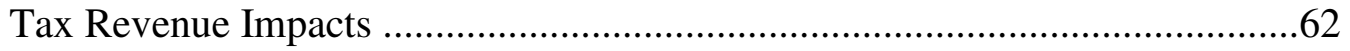

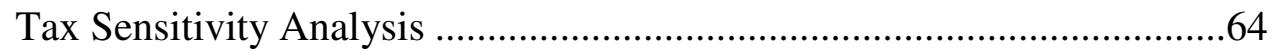

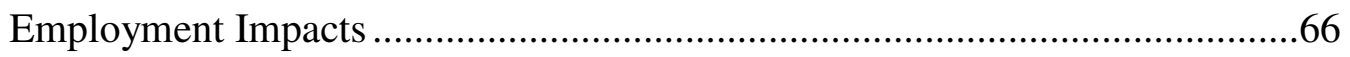

Employment Sensitivity Analysis .................................................68

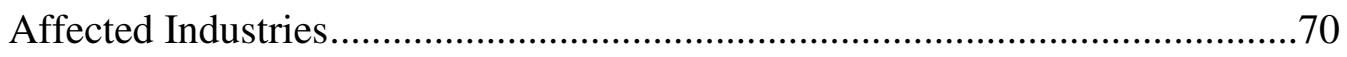

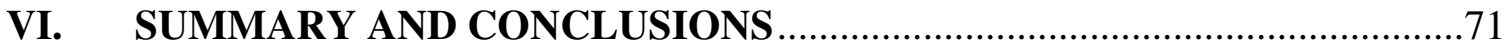

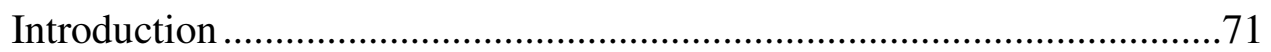

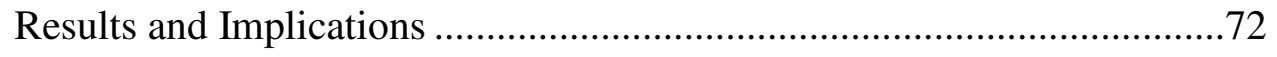

Opportunities for Further Research ........................................................ 73

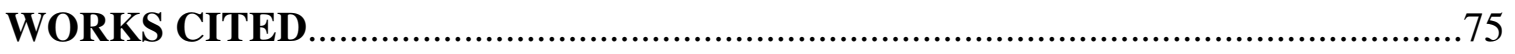

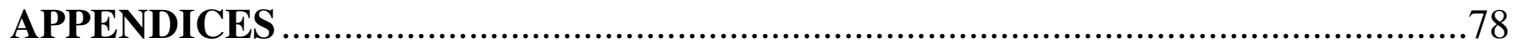




\section{LIST OF TABLES}

Page

\section{CHAPTER}

\section{RESULTS}

Table 5-1: Potential Output Losses Based on Model RPCs.......................................55

Table 5-2: Sensitivity Analysis - Potential Output Losses Based on 100\% RPC .......57

Table 5-3: Potential Value-Added Losses Based on Model RPCs .............................59

Table 5-4: Sensitivity Analysis - Potential

Value-Added Losses Based on 100\% RPC

Table 5-5: Potential Tax Revenue Losses Based on Model RPCs.

Table 5-6: Sensitivity Analysis - Potential

Tax Revenue Losses Based on 100\% RPC

Table 5-7: Potential Employment Losses Based on Model RPCs

Table 5-8: Sensitivity Analysis - Potential

Employment Losses Based on 100\% RPC 


\section{CHAPTER I:}

\section{INTRODUCTION}

In the 1970's, Stanislaus County recognized that the disposal of food processing byproducts represented a logistical and environmental dilemma. The belief at the time was that disposal could be handled in a more efficient manner, which would benefit all stakeholders. In 1978, the county took a proactive stance on the issue and aggregated a group of producers, UC extension agents, food processors, and other interested parties to discuss an improved approach to agricultural byproduct disposal (McHargue, 2001). As a result of this collaboration, the county developed the Stanislaus County Food Processing Byproduct Use Program. The program allows regional food processors to appropriate their byproducts to local agricultural producers, who then use them as supplements to livestock feed or soil amendments. The county, through a self-supporting permitting process, oversees how producers utilize the byproduct to minimize negative externalities of the program (“Action Agenda Summary", 2006).

Since its inception over $6 \mathrm{M}$ tons of byproduct has been diverted from landfills and used by agricultural producers. However, the Regional Water Quality Control Board (RWQCB) has voiced concerns that the Food Processing Byproduct Use Program may jeopardize the quality of local groundwater. The RWQCB recommended that the involved parties begin monitoring groundwater pollutants. This practice would represent a significant increase in the program's operating costs. To offset these expenses, the county would need to increase the cost of the permitting process and participating 
producers would incur increased expenses for program monitoring ("Action Agenda Summary", 2006). This incremental expense would make the program less viable for all participants.

Given the possibility of incorporating groundwater monitoring into the program, food processors and agricultural producers have investigated the potential cost impact. A few of the processors in Stanislaus and San Joaquin County have concluded that the groundwater monitoring system would make the program prohibitively expensive. They believe that the change would preclude their continued involvement. Furthermore, they asserted that the current program has allowed them to maintain their competitiveness and position in the local economy. Some processors have indicated that without the program in its current state, they would consider relocating outside of the region. Given the increasing importance of the food processing sector to the Stanislaus and San Joaquin County economies, an improved understanding of the nature and extent of the industry and its economic contributions is necessary.

This study is designed to quantify the regional economic impact of the food processing industry in Stanislaus and San Joaquin County. It also investigates the economic consequences of a food processor leaving the region as a result of changes made to the current Stanislaus County Food Processing Byproduct Use Program.

\section{$\underline{\text { Objectives }}$}

1. Research and identify the importance of waste reduction and diversion in the US, California, and Stanislaus/San Joaquin County

2. Describe the regional economic and environmental significance of the Stanislaus County Food Processing Byproduct Use Program to the food processing industry 
3. Quantify the current regional economic contribution of the food processing industry in Stanislaus and San Joaquin County

4. Estimate the economic effects of various changes in the composition of the local food processing industry

\section{Background}

\section{National Waste Production}

US population growth is straining the capacity of domestic landfills as they struggle to keep up with the copious production of municipal waste. In 2006, the US Census Bureau estimated that there were 300M people in the US (Tolbert, 2006). While this represented a milestone for the country and the economy, it is indicative of a growing level of stress for the nation's landfills. The population increase has resulted in a proportional decrease in landfill capacity, which is further compounded by the fact that per capita waste generation has experienced a marked increase from 2.7 to $4.5 \mathrm{lbs}$ per day since 1960 ("Municipal Solid Waste", 2006). Each of these factors has contributed to the increase in the pollution emanating from local dumping sites.

\section{National Recycling Rates}

In an effort to address this problem, numerous recycling programs have been implemented across the nation. In 2005, the United States generated 245M tons of municipal solid waste, with an average recycling rate of $32 \%$ or approximately $72 \mathrm{M}$ tons ("Municipal Solid Waste", 2006). While this is a significant accomplishment, the rate of recycling is not enough to negate the issues caused by current waste production. As a 
result, there is increasing concern for the integrity of the nation's water supply and general air quality.

\section{California Waste and Recycling}

According to the US Census Bureau, California's population was 36.8M people in 2008, making it the most populous state in the nation (2008). With such a large population it is critical for California to manage its waste disposal practices. In 2006, statewide waste production was estimated to be $92.2 \mathrm{M}$ tons, which represents an increase of over 40M tons in the last two decades and a substantial portion of total US waste generation (Stephens, 2006). Fortunately, this increase in production has been met by a similar increase in diversion. California has a high diversion rate of $54 \%$ or over $50.1 \mathrm{M}$ tons (Stephens, 2006). While this is an important accomplishment in the state's effort to preserve its dwindling landfill space, the growth of the population continues to be problematic for state landfill managers

Although it is natural to measure diversion by volume, it can also be measured based on its economic benefits. Numerous state studies have illustrated the benefits of diversion. One such study was conducted by Goldman and Ogishi on the economic impact of waste diversion on the California economy. The authors theorized that the benefits of diversion outweighed those of disposal by as much as 17\%-20\% (Goldman and Ogishi, 2001).

The results from the Goldman and Ogishi study reflect the economic climate of California. Based on the findings of the study, the 1999 rate of diversion generated $\$ 3.1 \mathrm{~B}$ in additional revenue and an extra 25,100 jobs (Goldman and Ogishi, 2001). Conversely, for every ton of waste diverted, they estimated that the state benefited from \$209 in total 
income impacts and \$290 in value-added impacts (Goldman and Ogishi, 2001). However, the monetary results represent conservative estimates of the benefits of diversion. Average estimates indicate that for every 1,000 tons of waste generated, disposal creates 2.5 jobs, but for the same amount of waste, diversion creates 4.7 opportunities in similar industries (Goldman and Ogishi, 2001).

\section{California Solid Waste Bill}

In an effort to minimize the externalities of state landfills and reap the benefits of diversion, Governor George Deukmejian signed Assembly Bill 939 (AB 939) into law on September 29, 1989 (Stanbra, 2007). The new law restructured California's waste logistics and ideas concerning sustainable waste management.

The updated strategy for waste management is based on the idea that prioritizing the waste entering landfills would result in a decrease in the volume. The bill required California counties and cities to develop plans to meet ambitious diversion goals. Each of the agendas was expected to include eight different components including source reduction, recycling, composting, special waste, public education and information, disposal facility capacity, funding, and integration (Stanbra, 2007). The initial mandate required that counties decrease their waste production $25 \%$ by 1995 and $50 \%$ by 2000 (Stanbra, 2007). Few municipalities have managed to meet these goals despite the threat of incurring fines. This is largely because the fines were rarely levied against the offending counties. Instead, the original deadlines were extended in the hope that local governments would continue to strive to meet their objectives (Stanbra, 2007). As a result, the effective rate of diversion for each jurisdiction varies; not only because of 
differences in initial waste production, but also because of inconsistent program compliance.

In response to mounting political pressure, each region was given the option of addressing waste diversion using its own strategy based on what local governments deemed prudent given their unique circumstances. Stanislaus County responded in a number of ways. However, one of the most successful waste diversion solutions employed, the Stanislaus County Food Processing Byproduct Use Program, was in place before the application of the new bill and was an integral component of the county's compliance with the new waste requirements. This program addresses waste disposal issues impacting the local food processing industry, the county's largest economic contributor.

\section{California Food Processing}

The structure of the food processing industry is transitioning from small local firms to large horizontally-integrated corporations. It functions under the dictates of a complex policy environment. Local firms cater to the requirements of three principle policy sets: farm and food sector policy, national industry policy, and national macroeconomic policy (Archibald, McCalla, and McCorkle, 1985). Policy makers seeking to effectively manipulate the industry must understand the interdependencies between producers, food processors and consumers. Archibald, McCalla and McCorkle describe how farm policy influences the price of inputs for food processors by affecting the intensity, composition and location of agricultural production (1985). They also point out that policies derived at the consumer level can impact food processing as part of farm and food sector policy; including grading, standards, and food safety requirements. 
National industry policy affects the industry by dictating social regulation, antitrust, corporate taxation, commercial trade policy regarding industry-specific tariffs, quotas and export subsidies, and government-sponsored research and development policies (Archibald, McCalla, and McCorkle, 1985). Lastly, they stipulate that national macroeconomic policy is influential in local food processing operations because it creates the economic environment in which the industry operates. These policies dictate exchange rates, wages, labor supply, and environmental welfare. This is particularly noteworthy in times of economic instability, when national policy is especially important to stabilize the industry. "A result of the interaction of macroinstability and structural change is that larger diverse firms have increased resource flexibility, which allows them to cope better with a dynamic economic environment" (Archibald, McCalla, and McCorkle, 1985, p. 1153). Because food consumption is relatively stable, industries (i.e. food processing) that cater to this need have a relatively consistent demand. This is largely because demand for processed food items is relatively inelastic and does not incur significant change during times of economic instability by comparison to other manufacturing industries (RDI). This is evidenced by the relative strength of the industry in the current economic recession. This stability can be attractive to a region because industries that support food consumption are a reliable tax basis and source of employment.

This is particularly noteworthy in California where the industry is very large. According to the 2007 Economic Census, there were 673 establishments in the fruit and vegetable canning industry in California. They employ 57,189 people who are paid over \$2B annually (“Sector 31”, 2007). Stanislaus and San Joaquin Counties constitute a 
significant percentage of this industry. They represent the sixth and seventh ranked counties in California with respect to agricultural output ("Summary of California County”, 2006). Fruit and vegetable canning and drying is the largest industry in Stanislaus County based on output (Olson and Lindall, 2004). Due to the volume of processed waste product and narrow profit margins, the industry is highly affected by restrictions on disposal activity.

\section{Food Processing Byproduct Use Program}

In an effort to reduce the strain on local landfills, the Stanislaus County Food Processing Byproduct Use Program was established in 1978 to address escalating concern surrounding the disposal of food processing residues, defined as waste materials generated from product processing, such as culls, stems, and other fruit and vegetable byproducts ("Stanislaus County Food Processing", 2006). The program redirects these wastes to operations where they serve as alternative inputs for other agricultural processes, such as animal feeds or soil amendments. During the first two decades of the program, more than $6 \mathrm{M}$ tons of food residue was diverted to other beneficial applications ("Action Agenda Summary", 2006). If not for the program, these wastes would have been disposed of in local landfills and the county would be non-compliant with the diversion requirements of $\mathrm{AB} 939$.

To ensure the program has minimal externalities, candidates must complete a permitting process to participate. In order to obtain a byproduct application permit for a given location a detailed plan of operation must be submitted. This application must include information regarding the drainage system, the daily maximum amount of residue expected, and the residue handling method (McHargue, 2001). To further guarantee the 
health of the program, the county frequently conducts inspections at each site during the season the participant is receiving the byproduct (McHargue, 2001). Each inspection includes an analysis of the fly population, unfavorable odors, and improper drainage as part of an effective approach to minimizing program externalities.

Program participants include dairies, feedlots, crops with land spreading operations, and animal feed processors (McHargue, 2001). Most of the byproduct entering these facilities originates from fruit and vegetable processing establishments within Stanislaus and San Joaquin Counties. As a result these counties derive the greatest benefit from the success of the program. Each disposal location is obligated to keep records regarding delivery dates, types of residue, amount of residue, and the hauling companies used in its delivery (McHargue, 2001). This ensures that the program's operations are accurately monitored and regulated. Additionally, it guarantees that the funding for the program varies proportionally with the time consumed by each operation. The land owners receiving the byproduct are charged for the inspector's hours, thereby generating the income required to fund the program. This makes it an environmentally and fiscally sound solution for a major waste management issue.

While there is a substantial fiscal incentive for the program, it is also important to consider the cost of the disposal alternatives if the program were to be discontinued. Currently, the program provides an economically efficient channel for disposal. Without this outlet for their byproducts, food processors could face a large increase in their disposal expenses. For processors in the county, the absence of this program would mean that their byproducts would be hauled to neighboring landfills at increased expense; not 
only exacerbating the problem of decreasing landfill space, but also contributing to increases in air pollution as a result of the trucks hauling the byproduct.

\section{Organization of the Thesis}

This thesis is organized into six chapters. Chapter II is a review of previous literature pertaining to regional economic analysis. This section has particular emphasis on input-output modeling and the existing studies whose methodologies served as the foundation for this work. Chapter III focuses on the basic concepts and theories of inputoutput modeling, including a discussion of the tables and equations employed in the modeling process. A review of IMPLAN, data collection, data sources and the processes employed in this study comprises Chapter IV. Chapter V addresses the results of the analyses and Chapter VI discusses the conclusions gained from this research and suggests options for continued study. 


\section{CHAPTER II:}

\section{LITERATURE REVIEW}

\section{Introduction}

The objective of this chapter is to review the literature pertaining to regional economic analysis. This area of study has had increased attention due to advancements in computer technology. As a result, regional economic analysis literature has inundated academic, professional and political forums. The following sections review a representative selection of the relevant literature. This assessment begins with a review of the different model classifications, including a discussion of how these classifications apply to the IMPLAN modeling software. The second section is a discussion of the types

of regional economic models commonly featured in the literature; which transitions into a discussion of the virtues of input-output (I/O) modeling and the alternative assumptions that are frequently used. Again, a discussion of how these methodologies apply to IMPLAN is incorporated. This is followed by a review of the advantages and disadvantages of input-output modeling and IMPLAN for the purposes of regional economic analysis. Finally, a review of the studies employing input-output models and the IMPLAN software is included, along with any pertinent aspects of their methodologies and the results they achieved. It is important to note that there is a preponderance of IMPLAN-based studies available. In an effort to narrow the focus of this analysis, only peer-reviewed studies were considered. 


\section{$\underline{\text { Model Classifications }}$}

\section{Structural vs. Nonstructural Models}

There are several different classifications used to characterize economic models. In his book, Regional Economic Modeling, Treyz identifies two distinct classifications that encompass all models, structural and nonstructural (Schlosser, 2008; Treyz, 2006). Structural models use backward linkages to predict the direct and indirect impacts of economic activities (Schlosser, 2008; Treyz, 2006). In his 2006 work, Shields postulated that the strength of the structural model stems from its flexibility with respect to policy analysis (Schlosser, 2008; Treyz, 1993). In contrast, nonstructural models utilize historic trends to forecast values of population, employment, and income (Schlosser, 2008; Treyz, 2006). Again Shields weighs in, stating that nonstructural models are marked by inflexibility and are not easily manipulated to accommodate the specific needs of a particular situation (2006).

IMPLAN - the input-output software used for this study - is an example of a structural model. It uses known economic linkages to predict the potential impact of a given activity, such as changes in tax policy or (in the case of this study) changes in the Food Processing Byproduct Use Program.

\section{Fixed-Price vs. Price-Endogenous Models}

In their 1991 paper, Haggblade, Hammer, and Hazell give another approach to model classification. They made distinctions between fixed-price and price-endogenous models. IMPLAN is considered a fixed-price model, so for the purposes of this study fixed-price models will be discussed in further detail. 
In their paper, Haggblade, Hammer and Hazell identified three types of fixedprice models: economic base (EB), input-output (I/O), and semi-input-output (SIO) (1991). To develop multipliers under a fixed-price model, all goods and services are subjectively categorized as tradable or nontradable (Haggblade, Hammer, and Hazell, 1991). Haggblade, Hammer and Hazell identified three assumptions that define all models under this definition (1991). First, they assume that increased production of tradable goods is a key component of regional economic growth. Second, all fixed-price models adhere to the standard Leontief assumption that all input coefficients and production functions are fixed. Third, they assume that all prices for tradable and nontradable goods are "fixed"; hence the fixed-price moniker (Haggblade, Hammer, and Hazell, 1991).

Advocates of fixed-price models rationalize constant prices for tradable goods by arguing that the economies being analyzed are small, open regional economies that are subjected to exogenously determined prices (Haggblade, Hammer, and Hazell, 1991). This is reasonable for the purposes of this research, because the study area was developed based on the economy of only one California county. Conversely, their justification for fixed-prices with respect to nontradable good relies on the "supply-side assumptions of fixed technical coefficients, perfectly elastic supplies of inputs and consequently of output" (Haggblade, Hammer, and Hazell, 1991, p. 362). Haggblade, Hammer, and Hazell recognized these assumptions are plausible under certain economic conditions (1991). They also stipulated that some circumstances are not amenable to such conjecture, such as economies with labor or capacity shortages. However, calculating Stanislaus County's supply-side deficits is beyond the scope of this study. For the 
purposes of this analysis, the assumptions inherent to fixed-price models will be considered realistic.

\section{$\underline{\text { Regional Economic Models }}$}

A number of methodologies have been established as sound approaches to regional economic modeling and analysis. In his 2006 book, Shields recognizes three specific models: computable general equilibrium (CGE) models, input-output (I/O) models, and regional econometric models (Schlosser, 2008; Shields, 2006). While regional economic models are developed under the auspices of multiple methodologies, recent technological developments have resulted in renewed interest in input-output modeling.

\section{Input-Output Models}

Input-output models illustrate the existing value of each industry and forecast values of changes in output, employment, and value added resulting from exogenous stimuli. They illustrate the value of the relationships between consumers, industries and institutions. They also approximate the relative value of each of the industrial sectors and their importance in the regional economy (Deller, Sumathi, and Marcouiller, 1993). For the purposes of this study, an I/O modeling software was employed to estimate the value of the food processing industry. The creators of IMPLAN, Olson and Lindall, define input-output analysis as "a means of examining relationships within an economy both between businesses and between businesses and final consumers" (Olson and Lindall, 2004, p. 95). 
This type of model is ideal for the purposes of this study because it provides a framework for easily manipulating the data to accurately reflect the scenario being studied.

While the positive attributes of the general input-output approach are widely acknowledged, there is continued debate regarding the different types of I/O models and how to integrate the conflicting methodologies.

\section{Types of Input-Output Models}

There are two types of input-output models, the Leontief model and the make-use model. Guo, Lawson, and Planting illustrate the distinctions between the two approaches in their 2002 work for the Bureau of Economic Analysis (BEA).

The Leontief I/O derives its name from the economist who developed the model in the 1930s, Wassily Leontief, who was later honored for his contributions to inputoutput modeling with the Nobel Prize in Economics. His model is referred to as the symmetric model, a title which is reflective of the symmetric tables that serve as its foundation (Guo, Lawson, and Planting, 2002). The Leontief model is defined by the fact that it makes no distinction between commodities and industries. The result is a one-toone relationship indicating that each industry produces only one commodity and therefore, each commodity can only be produced by a single industry (Guo, Lawson, and Planting, 2002). The model framework is developed using an intermediate transaction table, a final demand vector, and a value-added vector. As dictated by this methodology, total output can be calculated either by adding intermediate output and the value of final demands or by combining intermediate inputs and value-added. The direct nature of the relationship between commodities and industries indicates that the direct-inputcoefficient matrix and the total requirements matrix produce both industry-by-industry 
and commodity-by-industry tables (Guo, Lawson, and Planting, 2002). Under the assumptions of the Leontief model they are synonymous.

The make-use model was pioneered by the United Nations as a component of the 1968 System of National Accounts (1968 SNA). This input-output innovation expanded upon the concepts introduced by Leontief. The change resulted in a more pragmatic economic model development by incorporating byproducts into each industry's product mix, which meant that each industry could produce more than one commodity (Guo, Lawson, and Planting, 2002). The make-use model substitutes the Leontief framework with two primary matrices, the make matrix and the use matrix, representing outputs and inputs, respectively. This model was designed to address the issues encountered from increasing diversity in industrial production. This is accomplished by eliminating the standard Leontief assumption of one-to-one relationships and allowing each industry to produce multiple commodities (Guo, Lawson, and Planting, 2002). Consequently, a model constructed under the make-use system may not have the same number of industries and commodities. In this situation, the use matrix (which is developed on a commodity-by-industry basis) and the make matrix (which is developed on an industryby-commodity basis) will not be square. This results in asymmetrical matrices and represents a significant challenge for researchers.

The development of the make-use model created a paradox for economists. While the make-use model is a more accurate depiction of real-world economics, the Leontief model provides a superior framework for easily analyzing the relationships between industries and commodities through multipliers (Guo, Lawson, and Planting, 2002). Each of these tools exemplifies an important facet of economic modeling, which has resulted in 
major pressure in the academic community to develop a hybrid approach. This means finding a way to manipulate the asymmetric make-use model so that it can be easily incorporated into the symmetric Leontief model.

Numerous methods have been cultivated by researchers in an attempt to facilitate this conversion. Unfortunately, this effort has been marked by indecision on the part of the academic community concerning which of two alternative assumptions is to be incorporated into the model - the industry-technology assumption (ITA) or the commodity-technology assumption (CTA). These assumptions are necessitated by the asymmetry of the make-use tables which stems from secondary production. Despite the thorough research and exhaustive debate, no universal consensus has been established regarding the validity of either assumption (Guo, Lawson, and Planting, 2002).

The advantages and disadvantages of the alternative assumptions are discussed in greater detail in the following section.

\section{Alternative Technology Assumptions}

Since the development of the make-use model in 1968, the academic community has debated how to manipulate the asymmetric make-use matrices so they fit into the symmetric Leontief framework. According to the work by Guo, Lawson, and Planting, the debate has its primary focus on two alternative assumptions, the ITA and the CTA (2002). The ITA stipulates that all commodities and byproducts produced by an industry have the same production function (Olson and Lindall, 2004). The CTA employs the opposite approach. This assumption proposes each commodity's production function is unrelated to the producing industry. There are advantages and disadvantages to each assumption. Gou, Lawson, and Planting stated that "these tend to mirror one another- 
that is, the advantages of one tend to avoid or solve the disadvantages of the other" (2002, p. 6).

In their work for the BEA, Guo, Lawson, and Planting recognized several other literary works that address this issue (2002). They found that much of the academic community considers the ITA to be unrealistic because it does not adhere to the standards of a number of axiomatic economic theories (Guo, Lawson, and Planting, 2002). They identified a number of academic dissertations as significant contributions to this argument. The papers by Almon (1970, 2000); Raa, Chakraborty and Small (1984); and Steenage (1990) were amongst those cited. Raa and associates further contributed to the argument by asserting that the "industry technology assumption implies that the choice of the base year prices is not only a matter of scaling but becomes an essential determinant of the representation of technology" (Raa, Chakraborty, and Small, 1984, p. 89). They use this as support for their argument that the ITA is not a plausible approach to I/O modeling. Because much of the academic community regards the ITA as unrealistic, the CTA is generally considered to be the more pragmatic alternative (Guo, Lawson, and Planting, 2002).

However, despite the argument against it, the ITA continues to be widely employed in economic research. This is largely because the ITA has some practical advantages over the CTA. The ITA is able to accommodate the asymmetry of the make and use tables and it always produces nonnegative results (Guo, Lawson, and Planting, 2002). In contrast the CTA often results in negative output numbers, which are generally considered impossible under real world conditions (Guo, Lawson, and Planting, 2002). 
The practical advantages of the ITA are the reason it is employed by IMPLAN despite the merits of the CTA.

Many researchers have attempted to address the inadequacies of the CTA methodology. The negative output numbers have been implicated as a side effect of data collection and aggregation errors (Guo, Lawson, and Planting, 2002; Raa, Chakraborty, and Small, 1984). Raa, Chakraborty and Small suggested that under perfect circumstances data could be collected that would not produce negative coefficients under the CTA (1984). However, in their research, Guo, Lawson and Planting encountered studies that impugn this theory based on evidence that negatives are an inherent part of this assumption because the CTA "breaks the internal linkages of commodity flows" (2002, p. 7).

Guo, Lawson and Planting briefly discussed the efforts of Almon in his 1970 study (2002). Almon developed an algorithmic method for eliminating negative integers; however, Guo, Lawson and Planting and Raa, Chakraborty and Small criticized his approach in which negative variables in the $\mathrm{I} / \mathrm{O}$ calculations are balanced in an iterative procedure (Guo, Lawson, and Planting, 2002; Almon, 1984; Raa, Chakraborty, and Small, 1984). The approach used was not viewed as a valid method of manipulating the data to eliminate negative results.

Finally, Raa, Chakraborty, and Small suggested an alternative to the CTA in their 1984 work. They introduced a hybrid solution that draws upon the principles of both the commodity and the byproducts assumptions. No literature could be found confirming the legitimacy of the Raa, Chakraborty and Small approach, so despite the many alternatives a universally accepted assumption has not been validated. 
The practicality of the ITA is the reason it is used by IMPLAN despite the merits of the CTA and other assumptions. IMPLAN distinguishes between commodities and industries and is generally considered a make-use model. However, its asymmetric tables fit into the Leontief framework because it operates within the restrictions of the ITA.

\section{Advantages of Input-Output Models}

The practical advantages of IMPLAN extend beyond the virtues of the ITA. For many users, the appeal of input-output models is the sectoral detail they provide (Leones, Schluter, and Goldman, 1994). They itemize the monetary value of any change in the economy on an industry-by-industry basis. IMPLAN introduces a number of additional advantages. First, it serves as a vessel for computational simulation of an economic impact, which significantly expedites the process of model development, making inputoutput a more attractive option in situations where time is a constraining factor. This is important when policy decisions are at stake, as is the case in Stanislaus County. Second, it allows the user to easily define a study area based on the unique requirements of the study. Also, it facilitates increased flexibility, by allowing users to manipulate data based on the individual needs of the study. If necessary, the user can influence almost every aspect of the study area to generate a model that precisely reflects the parameters of their study area. Lastly, when developing an I/O model using IMPLAN, many scientists recommend collecting survey-based, region-specific data to develop a model based on the specific economy of the study area (Leones, Schluter, and Goldman, 1994).

In its most basic form, IMPLAN provides a framework for developing a model based on national averages combined with regional data. However, it is important to note that it also serves as a medium for developing hybrid models based on unique data 
developed by the user. Survey-based models are not universally acknowledged as superior to nonsurvey models because data collection is often flawed. If the researcher deems the default IMPLAN figures to be accurate it eliminates the need for costly data collection. The practical facets of I/O modeling and IMPLAN make it an invaluable tool for developing regional economic models and running impact analyses under the demands of real world circumstances. While economic theory has provided a framework for model development, IMPLAN provides a venue for developing models that estimate the economic impact of various shocks to a defined region.

\section{Disadvantages of Input-Output Models}

As outlined above, input-output has been recognized for its flexibility as a vehicle for regional economic modeling. However, a number of published works have highlighted some of the negative aspects of its methodology. Haggblade, Hammer and Hazell criticized the multipliers derived from all fixed-price models, particularly inputoutput (1991). This type of model generates the largest multipliers of all the fixed-price models, which by many are considered to be unrealistically large (Haggblade, Hammer, and Hazell, 1991). They also rely on national coefficients which may not accurately reflect the local economy (Shields and Willits, 2003). To validate their point, Haggblade, Hammer and Hazell ran three analyses on identical economies based on the assumptions of the three fixed-price models (1991). They found that the SIO model generated the most realistic multipliers. By comparison, the $\mathrm{I} / \mathrm{O}$ model resulted in multipliers that were ten times higher. Haggblade, Hammer and Hazell believe that "the dramatically different scale arises because the I/O model allows an initial injection of tradable income to 
stimulate demand not only for nontradables but for more tradables as well" (1991, p. $365)$.

Additional attention has been drawn to the underlying assumptions of fixed-price models. The static linear nature of fixed-price models is considered by many to be an unrealistic representation of real world economies. Archibald, McCalla, and McCorkle analyzed the dynamics of the food processing industry and voiced concern that a static model could not accurately reflect the complexity of the industry and is unable to incorporate economies of size (1985). They accused conventional models of being incapable of accommodating the complexities of a dynamic regional economy (Archibald, McCalla, and McCorkle, 1985). The assumption of perfectly elastic supply of nontradables draws some negative attention because the principle is often considered to be implausible. It implicitly assumes an unlimited labor supply, which is rarely the case.

Lazarus conducted a study to compare IMPLAN RPCs to real-world RPCs. His research revealed some discrepancies (2002). However, he recognized that his work only considered a single county - Martin County, Minnesota - and a single industry - the swine industry (Lazarus, 2002). No other studies could be found to corroborate his findings, so for the purposes of this study IMPLAN food processing RPCs are considered reliable.

Lastly, while input-output models are renowned as excellent vehicles for estimating backward linkages based on an initial change in the primary industry, approximating forward linkages is not as reliable and many models are unable to accommodate this facet of economic activity. Multipliers do not capture forward linkages. These exist when output from the primary industry serves as an input to another 
sector and thereby changes the secondary industry's output level (Hamilton et al., 1991). Forward linkages are only present in economies in which forward industries have supply constraints and would otherwise expand their production operation (Hamilton et al., 1991). Consequently, in situations where the industry of interest generates a commodity that serves as a major input for another industry, multipliers may actually underestimate the impact of an economic change.

\section{Input-Output Studies}

Regardless of the benefits or shortcomings of input-output models, there is an abundance of literature available that references its methodologies. This is often the result of a political environment that is increasingly focused on monitoring policy decisions and expenditures. In response to these pressures, state and local governments often solicit regional economic analyses as part of an informed approach to policy approval and implementation. These analyses assess the state of the economy and frequently include estimates of the fiscal and employment impacts of policy decisions. The following section is a review of the literature concerning regional I/O models and IMPLAN.

McNicoll and Baird developed an input-output model representing the effect of the oil industry on the Shetland economy (1980). They sought to temporally evaluate the changes in the industry between 1976 and 1985 by employing the basic Leontief equation with a spatial element. This inclusion required the authors to recognize some key assumptions with respect to trade and technology. The use of the Leontief equation implies that the authors are assuming that industries produce only a single commodity. In

other words, they are using the ITA as an inherent part of the Leontief methodology. The spatial component allowed the authors to apply an additional assumption. They assumed 
that the domestic flow coefficient remained constant. This implies that the flow of goods between regions is assumed to be stable and unchanging. Using the Leontief model as the foundation for their study, McNicoll and Baird outlined three objectives for their work: multiplier analysis, impact study, and forecasting (1980).

In their paper, the authors recognized three usual categories of multipliers: output, value-added, and employment. For output, they opted to use Type II multipliers for their analysis, implying that they included direct, indirect, and induced effects. This makes their results relatively conservative compared to those that would be obtained using Type SAM multipliers. They also calculated output and employment multipliers so they could be used for impact analysis. For the purposes of forecasting, the authors had to develop the region's domestic flow matrix and final demand numbers. To accomplish this, a simplified hybrid model was developed. This forecasting model included only the output numbers for oil and assumed that the domestic flow coefficient matrix would be the same for 1985 as for 1976 . This assumption was necessitated by the limited availability of data at the time. McNicoll and Baird rationalized the use of these assumptions with two points (1980). They argued that in a rural economy such as Shetland, domestic flow coefficients are slow to change. Their work in previous inter-temporal studies was cited to corroborate this assumption. Their second point was that intermediate output, the component of total output being forecast for the purpose of the study, was relatively small and would have minimal impact on the results. Based on these assumptions the authors used the Leontief equation and the associated iterative processes to estimate changes in output, employment, income, population, etc. The multipliers derived from 
$\mathrm{I} / \mathrm{O}$ analysis are important to policymakers because they enumerate the potential value of a change in a given industry and allow for reliable forecasting estimates.

The study was successful in assessing two significant issues based on the transactions table and via numerous multiplier analyses. Primarily that the industry had a comparably large effect on the regional economy. Secondly, they ascertained that the industry's employment and value-added effects are relatively minimal "because of its limited degree of integration with the local economy" (McNicoll and Baird, 1980, p. 990). These findings demonstrate the importance of vertical integration and the multiplier effect in determining the ripple effects induced by a change in an industry. Industries with minimal vertical integration have small multipliers and therefore the indirect and induced effects of changes in those industries will be minimal. This fact will be of significance in the Stanislaus study because the multipliers will reflect the degree of vertical integration and determine how important the food processing industry is to the local economy.

The McNicoll and Baird study is an example of a regional economic study in its most basic form. However, most studies now utilize modeling software. Leones, Schluter, and Goldman reviewed the existing state level studies on the role of agriculture (1994). Their work included twenty-seven studies. Fourteen of these were conducted using an input-output framework, eleven of which were developed using IMPLAN (Leones, Schluter, and Goldman, 1994). IMPLAN has become a widely used tool for economic modeling. The following is a survey of peer-reviewed studies that used IMPLAN to conduct their analyses. 
In his 2003 paper, Shields developed a hybrid IMPLAN model to estimate the economic importance of the environmental horticulture industry (EHI) to the northeastern U.S. He incorporated primary data collected in a statewide, industry survey, deemed necessary because IMPLAN doesn't provide the desired level of industry disaggregation or EHI-specific data. The survey was developed based on a Pennsylvania Department of Agriculture list of the 7,435 certified nursery growers and dealers in the state. A sample of 4,015 units was taken and of this section, 2,909 establishments were viable candidates for the survey. They were asked to provide proprietary information regarding income, employment, payroll, and taxes. Ultimately, 842 usable surveys were returned. Additionally, information for 26 of the large chain stores was obtained via direct contact with their national offices. Each of the participating establishments was assigned a "business type" based on its characteristics and categorized with similar entities. This allowed analyses to be run for each industry echelon.

Shields developed a unique EHI sector by aggregating the appropriate industries and manipulating the IMPLAN data based on the survey results (2003). This entailed altering the consumption data and changing the regional purchase coefficients. Based on the newly constructed model, he ran analyses based on both Type I and Type II multipliers. Shields then divided the Type II multipliers by the Type I to avoid double counting, a common problem in models analyzing multiple industries (2003). The results of his analysis indicated that the hybrid EHI industry had a value-added multiplier of 2.2 and an employment multiplier of 1.5. Ultimately, Shields postulated that the industry was a vital and expanding part of the northeastern agricultural economy, which had the potential to significantly contribute to the growth of the agricultural industry as a whole 
(2003). In other words, policy decisions regarding the industry should consider its potential to foster growth in the areas of gross state product, employment, and income.

Shields' study was concerned with agriculture's impact on an entire region. However, it is far more common to find studies that analyze agriculture's impact at the state level. This is because the industry is subject to state regulations. Therefore, it benefits policymakers to understand the value of agriculture to their state.

One example of a state level study was conducted by Tanjuakio, Hastings, and Tytys. In their 1996 work, they attempted to estimate the value of the agricultural industry to the Delaware state economy. Their efforts were concerned with the different definitions of agriculture and how those definitions affected the results of input-output analyses. To address this issue, Tanjuakio, Hastings and Tytys developed three definitions of agriculture ranging from the strictest definition, which only included production agriculture to the most liberal definition, which included not only production agriculture, but also agricultural input industries and food and fiber processing industries (1996). Based on the specific needs of this study, the authors opted to set the RPCs for the directly affected industries to zero to avoid double counting. This is often done in studies analyzing the economic effects of an aggregated group of industries and effectively prevents the industries from selling their outputs to each other (Tanjuakio, Hastings, and Tytys, 1996).

Outside of the changes made to the model RPCs, Tanjuakio, Hastings and Tytys, chose to develop their models based on the data provided by IMPLAN (1996). In addition to creating models based on the three definitions of agriculture, they also developed models using both Type I and Type III multipliers. As expected, given the 
broader definition of Type III multipliers, the multipliers derived from those analyses were much larger than those resulting from the Type I model. Based on these models, they obtained impact results pertaining to Delaware's total output, value-added and employment. The multipliers varied significantly depending on the definition of agriculture used in the analysis. One of their most important findings was agriculture's employment multipliers. Tanjuakio, Hastings and Tytys found that these ranged from10.898 to 30.537 (1996). Not only are the multipliers very large, but they experience a marked increase depending on the definition of agriculture. This suggests that great care should be taken in determining how an industry is defined to avoid unrealistic results.

Another state level study was conducted by extension economist, Broomhall under the Department of Agricultural Economics at Purdue University (1996). He was charged with estimating the impact of the agricultural industry on the Indiana economy. As in a number of Broomhall's studies, IMPLAN was the chosen medium for economic modeling. His previous research suggested that it provided conservative estimates of economic activity (Broomhall, 1996). In his 1996 paper, he chose to operate under the broadest definition of the word "agriculture". In fact, he incorporated data from the entire food system. For the purposes of his study, this may have been a reasonable decision. However, it is important to note that by defining agriculture in the broadest sense, his results are probably much higher than those who used a narrower definition, which was demonstrated in the study by Tanjuakio, Hastings and Tytys (1996). Broomhall defined five basic food related industries: farm inputs, farm production, food processing, 
wholesale and retail, and food service (1996). He did this by aggregating the pertinent IMPLAN industries to simplify the results.

Broomhall contends that the IMPLAN data regarding farm production, which are collected from the Census of Agriculture, are insufficient because of considerable data shortages (1996). In an effort to mitigate the consequences of this limitation, he supplemented the IMPLAN data with farm production and income data from the Indiana Agricultural Statistics Service, which he deemed to be more accurate. He stipulated that the other industries under review did not experience the same data shortages, so the IMPLAN numbers were considered viable. Broomhall also pointed out that he went to great lengths to avoid the issue of double counting (1996). However, he neglected to discuss exactly what actions he took to address the problem.

Broomhall's results indicated that Indiana's agricultural industry contributed $13.3 \%$ of total value-added ( $\$ 16.6 \mathrm{~B})$ and $17.3 \%$ of total employment $(500,000$ jobs) in the state (1996). He also determined that the farm sector represents a far greater percentage of the rural economy than the state economy. Conversely, the food processing sector as a part of the state economy is $40 \%$ larger than in rural regions (Broomhall, 1996). This makes evaluation of the Stanislaus system particularly important because it is an area that is very reliant on agriculture for economic stimulation and is therefore susceptible to changes in the agricultural economy.

The proliferation of agricultural policy has resulted in an abundance of state level studies regarding the agricultural industry. However, there is often a need for research with a narrower focus. Lazarus et al. developed a regional economic model to evaluate the economic impact of the Minnesota swine industry (2002). Their paper sought to 
determine the implications of the swine industry transitioning from small businesses to large enterprises (Lazarus et al., 2002). In their research they criticized the findings of a study by Thompson and Haskins, who postulated that firms of all sizes were equally likely to survive as the economy evolves (Thompson and Haskins, 1998; Lazarus et al., 2002).

They focused their efforts on four counties in the state that significantly contributed to swine production. This decision minimized both the cost and time of the operation. Data was collected from producers via a mail survey regarding all the major inputs for swine production and where they were purchased. Two hundred and seventytwo surveys were sent out and 111 were returned with usable information for a $41 \%$ response rate. Another $8 \%$ were found to have quit raising hogs. The survey was carefully worded to avoid the perception of bias with respect to product not purchased locally. This is often a problem because there is an assumed bias associated with goods purchased from outside the region. The authors acknowledged a mail survey limited the detail they would be able to achieve in their research. However, they decided that it was preferable to collect general information from many sources than to collect detailed information from a few.

This study also used IMPLAN to conduct the economic analysis. The authors distinguished between data collected for operations of different sizes and ran two separate analyses to represent each data set. Based on the information gathered during the preliminary stages of their research Lazarus et al. were able to enter unique purchase coefficients and production functions into the IMPLAN software so that the results would be representative of their specific study area (2002). Additionally, their survey provided 
them with regional purchase coefficients exclusive to their industry and study area. Their research indicated that transportation had the highest RPC (0.7), indicating that it was generally purchased locally. However, other RPCs varied significantly, with replacement boars having the lowest at 0.21 . Larger businesses had the potential for substantially higher multiplier effects because they inherently require the purchase of more of inputs. Lazarus et al. stipulated that if these are purchased locally, the study area economy will be subject to the ripple effects associated with increased activity (2002). However, larger operations are not as likely as smaller ones to make purchases locally. Therefore, they do not necessarily have higher multipliers than the smaller operations purchasing fewer inputs. The Minnesota study acknowledged this distinction and addressed it by reviewing the impacts on both the county and state level. At the state level there are fewer leakages than would be found with a study of a smaller region because most of the inputs are purchased within the state. They concluded that smaller operations provide more jobs, but the positions did not pay as much. In contrast, large operations provide better compensation, but they do not provide as many jobs. This leads to the obvious question... Which is better, more jobs or better jobs? Based on the results of the study, Lazarus et al. theorized that an industry based on smaller operations generates more economic activity (2002). Therefore, it would behoove policymakers to make decisions that encourage the growth of smaller operations in the industry.

\section{$\underline{\text { Summary }}$}

Numerous methodologies have been used to develop regional economic models, but input-output modeling has received attention recently as a conservative approach to analysis. As part of this development, IMPLAN has become a widely used mechanism 
for developing I/O multipliers for output, employment and value-added. While it does have some shortcomings, it is a particularly useful tool in situations when model flexibility is important or time is a constraining factor.

There is an abundance of literature regarding both input-output and IMPLAN. This study will further contribute to the field by analyzing a scenario specific to the Stanislaus County fruit processing economy. Ideally, it will assist policymakers in making informed decisions with respect to allocating agricultural resources. 


\section{CHAPTER III:}

\section{THEORETICAL MODEL}

\section{Introduction}

The objective of this chapter is to present the basic concepts behind input-output analysis, which serves as the structural foundation of IMPLAN.

To quantify the importance of the food processors in Stanislaus and San Joaquin Counties who might use the Stanislaus County Food Processing Byproduct Use Program, an input-output model was employed. This tool allows modelers to illustrate the industry's influence on the local economy. Input-output modeling is a mechanism for examining relationships among firms, industries, and institutions within a local economy (Mulkey and Hodges, 2000). This approach is often used to analyze the impact of specific industry activity. It includes all of the fiscal transactions for a given time period. Holland and Yeo describe input-output modeling as a system that describes the cyclical movement of wealth and commodities in an economy (2001). Hall and Skaggs elaborate on this description by explaining that these models represent all consumption and production in an economy, which is organized into sectors categorized by industrial characteristics or enterprises (2003). Economic impact analyses are an integral tool for policy makers seeking to valuate the current economy and determine the potential consequences of economic activities (Broomhall, 1994).

This methodology was founded upon Leontief's work (Olson and Lindall, 2004). Input-output modeling serves as a vehicle for analyzing the interactions that shape a local 
economy. These interactions can occur as transactions between businesses or between businesses and final consumers (Olson and Lindall, 2004). They reflect the monetary transactions that shape the market within a specified time period (Olson and Lindall, 2004). The I/O system yields mathematical formulae that mirror these iterations and serve as a means of analyzing the effects of changes within the economy (impact analysis) (Olson and Lindall, 2004). However, because of the variable input data, Olson and Lindall stipulate that it is important to regard the results of any I/O study as general estimation rather than predictions (2004).

Input-output studies are often defined by the manner in which the data is collected. Under this system there are two unique classifications - primary and secondary studies (Olson and Lindall, 2004). Primary input-output studies represent a class of models constructed using data that was derived from direct study of the affected industries (Olson and Lindall, 2004). There are several examples of primary studies that have been conducted on a national level in a number of countries; one example is the U.S.'s Benchmark Study of Input-Output Accounts (Olson and Lindall, 2004). Primary studies are generally considered to be more accurate, but few are conducted on the state or county level because the cost of data collection is often prohibitive. Alternatively, the methodology of secondary studies requires analysts to collect data from existing databases to develop input-output accounts (Olson and Lindall, 2004). This data is typically collected from accounts generated through primary input-output research. IMPLAN is considered a secondary input-output modeling system because it utilizes data that was previously collected by a number of U.S. government agencies (Olson and Lindall, 2004). 


\section{Industry v. Commodity}

As part of a general understanding of $\mathrm{I} / \mathrm{O}$, it is important to understand the distinction between "industry" and "commodity". These terms are often used interchangeably. However, in the context of I/O analysis, they represent two decidedly different concepts. Unfortunately, these unique ideas often foster confusion because industries and commodities share the same names. The term "industry" refers specifically to businesses in a local economy (Olson and Lindall, 2004). The term "commodity" refers to the goods and services themselves; those used by the industries in the production process (Olson and Lindall, 2004). Industries can - and often do - produce multiple commodities. However, their primary commodity serves as their namesake. All other products are known as secondary commodities or byproducts (Olson and Lindall, 2004). This is important to remember when manipulating the asymmetric tables of a make-use model which was discussed in Chapter II.

\section{Key Assumptions of Input-Output Modeling}

As a cornerstone of the IMPLAN methodology, it is essential to understand the assumptions that serve as the foundation of $\mathrm{I} / \mathrm{O}$ analysis before considering the results of any such study. These include 1) Constant Returns to Scale, 2) No Supply Constraints, 3) Fixed Commodity Input Structure, 4) Homogenous Sector Output, 5) the Industry Technology Assumption, and 6) the Market Share Assumption.

The first assumption dictates that the production functions are assumed to have constant returns to scale (Olson and Lindall, 2004). These equations are assumed to be 
linear (Olson and Lindall, 2004). In other words, if increases in demand require an increase in output, all inputs will increase proportionately (Olson and Lindall, 2004).

The following assumption indicates that for the purposes of model construction there are no supply constraints (Olson and Lindall, 2004). This is a relatively self explanatory assumption in that production is assumed to be uninhibited by supply (Olson and Lindall, 2004). This implicitly assumes that the only force dictating a business's output is demand.

The fixed commodity input structure assumption specifies that a company has little flexibility with respect to its required inputs (Olson and Lindall, 2004). This prohibits the use of substitute goods for the purpose of effectively managing total cost. Inherent in this assumption is the understanding that exogenous changes in the economy will not result in a change in a business's input structure.

The fourth assumption requires the same homogeneity with respect to sector (industry) output. This implies that if there is an increase in the output of an industry's primary commodity, there will be a proportional increase in all of its byproducts, and vice versa (Olson and Lindall, 2004). In other words, the product mix ratio remains the same regardless of any change in output.

The industry technology assumption (discussed in Chapter II) asserts that an industry employs the same mechanisms and technologies to produce all of its products primary and secondary (Olson and Lindall, 2004). This is significant because many industries produce byproducts in addition to their primary commodity. This assumption also stipulates that the same production function is triggered regardless of which commodity is purchased (Olson and Lindall, 2004). Conversely, this implies that the 
same commodity purchased from different industries will catalyze different production functions (Olson and Lindall, 2004).

Lastly, the market share assumption is based on the principle that an industry contributes to consumption in the same volume that it contributes to total production (Olson and Lindall, 2004). In other words, an industry's market share is the same with respect to production and consumption. Olson and Lindall illustrate this principal mathematically. For example, an industry market share coefficient is calculated by dividing industry production by total regional market production of a commodity. They further clarify the point in the following example: Industry A spends .005 percent of every dollar on Commodity A as part of its production function. If Industry C is responsible for $22.2 \%$ of Commodity A's production, then the market shares assumption postulates that $22.2 \%$ of Industry A's need for Commodity A will be satisfied by Industry C. This can be mathematically represented as $0.222 * 0.005=0.0011$ (Olson and Lindall, 2004).

These six assumptions provide a basis for input-output modeling and frame the results of any study. It is essential to understand them as part of the IMPLAN analysis.

\section{Descriptive Model}

When developing an I/O model, the descriptive model is always the first to be constructed because it serves as the catalyst for the calculations in the predictive model. This element and all of its data components are indicative of the current economic climate in the user determined study area (Olson and Lindall, 2004). It incorporates all the data from the IMPLAN databases into regional economic accounts (Olson and Lindall, 2004). These are a reflection of the flow of currency in the region from 
purchasers to producers. Developing economic accounts is accomplished through a process in which study area data is applied to the absorption and byproducts matrices (Olson and Lindall, 2004).

An understanding of the financial accounting system transitions into an appreciation for the I/O structure since both are a reflection of income and expenditures. Input-output follows the flow of money between business entities and final consumers (Olson and Lindall, 2004). The I/O accounting system is comparable to traditional financial accounting T-accounts (Olson and Lindall, 2004). As in any T-Account, receipts are recorded on the right hand side of the diagram and expenditures are recorded on the left. Receipts are any business income originating from other businesses or institutions (Olson and Lindall, 2004). The expenditures on the left hand side reflect the costs of operation for a business to produce their goods and services (Olson and Lindall, 2004). Similar to any financial balance sheet, income and expenditures must mirror each other. To fully balance the account, profit is used to correlate expenditures with receipts (Olson and Lindall, 2004).

The descriptive model incorporates a number of components: input-output accounting tables, trade flows, and social accounting data (Olson and Lindall, 2004).

\section{Input-Output Accounting}

As part of the descriptive model, input-output accounting substitutes the basic Taccounts with a number of tables that mimic the flow of goods and services with income and cost figures. These include the Use Table, the Value-Added Table, the Make Table, and the Final Demand Table (Olson and Lindall, 2004). It also incorporates derivations of these tables: the Absorption Table, the Byproducts Table, and the Market Shares Table 
(Olson and Lindall, 2004). For a full description of all these tables and how they fit into the input-output modeling process, see Olson and Lindall's IMPLAN Pro User's Guide.

\section{Trade Flows}

Trade flows describe the economic interactions between the study area and foreign economies - i.e. imports and exports (Olson and Lindall, 2004). These are especially important in descriptive model construction. The original IMPLAN data is reflective of total product in the region, including imported goods and services. However, when the descriptive model is constructed imports are eliminated (Olson and Lindall, 2004). This allows the user to review the inter-industry transactions that occur strictly within the study area. When local businesses have to purchase their inputs from regions outside the realm of the study area, it is known as a leakage (Olson and Lindall, 2004). Leakages are an indication of currency leaving the local economy. However, this description is somewhat arbitrary because the monetary value of the leakage is completely dependent on the size of the study area (Olson and Lindall, 2004). A very small study area (i.e. county or sub-county) will have considerable leakage because its size makes it probable that a consumer or industry will have to go outside the region to acquire the necessary goods. Conversely, a large study area (the state of California, for example) will have few leakages because most inputs are available within the region.

There are a number of mathematical approaches to estimating trade flows - these include Regional Purchase Coefficients (RPCs), Supply/Demand Pooling, and Location Quotients (Olson and Lindall, 2004). RPCs are the default method in IMPLAN, so they are thoroughly outlined for the purposes of this study. 


\section{Regional Purchase Coefficients}

Regional purchase coefficients are mathematical representations of the quantity of local demand satisfied by local supply (Olson and Lindall, 2004). For example, an RPC of 0.4 indicates that for every dollar of local demand, $40 \%$ is supplied by local producers. Conversely, this also implies that $60 \%$ of local demand is satisfied by imports (Olson and Lindall, 2004). This approach relies on the characteristics of the local economy to estimate trade flow numbers mathematically through econometrically-based equations (Olson and Lindall, 2004). The IMPLAN software generates these numbers automatically based on the study area's regional economic accounts (Olson and Lindall, 2004). Any alteration to an industry's trade flow data is ultimately a change in that industry's RPC. Determination of commodity RPCs is one of the most important forces shaping multiplier calculation. Regionally purchased commodities stimulate more local economic activity and therefore, generate a larger multiplier (Olson and Lindall, 2004). Multipliers are required for the developing the predictive model and will be discussed subsequently.

\section{Social Accounting Data}

The descriptive model also incorporates social accounting data with the regional economic accounts to analyze the ramifications of non-industrial transactions (Olson and Lindall, 2004). These transactions include payments made to taxes and those made to households and businesses by the government (Olson and Lindall, 2004). Input-output accounting embodies the movement of goods from producers to consumers. Social accounting matrices (SAMs) reflect the movement of wealth between institutions. Both are components of the descriptive model. 


\section{Predictive Model}

Input-output modeling is driven by final consumption and the iterative process of mathematically determining its economic effects (Olson and Lindall, 2004). The direct, indirect, and induced effects (discussed in the following section) of this process can be mathematically derived as sets of multipliers (Olson and Lindall, 2004). These represent the response of the economy to stimuli. The multipliers generated by this process reflect the change in output catalyzed by a one dollar change in final demand (Olson and Lindall, 2004). The predictive model is the embodiment of these I/O multipliers and is responsible for the forecasting aspect of the input-output analysis.

\section{Direct, Indirect, and Induced Effects}

IMPLAN has developed three descriptive classes to express economic impacts. These classes qualify each impact as either direct, indirect, or induced effects (Olson and Lindall, 2004). These titles are indicative of the manner in which the transaction affects the economy. Direct effects represent the impacts that are directly related to the event (Olson and Lindall, 2004). In terms of this study, direct effects are the dollar value directly associated with the departure of a firm or a downsizing in the food processing industry. These in turn produce ripple effects that echo throughout the industry known as indirect effects. These are changes that occur as other industries produce and sell more or less as a consequence of the direct effects in the study area (Olson and Lindall, 2004). The last class of economic impacts encompasses the induced effects. These occur as a result of changes in the direct and indirect effects. Impacts of this nature manifest as changes in local consumer spending resulting from direct and indirect changes in affected economic sectors (Olson and Lindall, 2004). 


\section{Summary}

These two models serve as the foundation of IMPLAN and all the associated

processes. The descriptive model is a reflection of the current study area, while the predictive model uses multipliers to represent the direct, indirect, and induced effects of an economic stimulus. IMPLAN uses these to model user-determined impacts. 


\section{CHAPTER IV:}

\section{METHODOLOGY}

\section{Introduction}

Chapter IV discusses the methodology used to complete the objectives of this study. This includes a discussion of the general merits of IMPLAN and an overview of the procedures used for data collection and manipulation as dictated by the software tool.

As previously discussed in Chapter II, there are a number of viable approaches to regional economic modeling: computable general equilibrium (CGE) models, inputoutput (I/O), and regional econometric models. Each of these methodologies has merits and shortfalls. For the purposes of this study, IMPLAN (an input-output software) was chosen because it was specifically developed for this type of research and it provides a reliable framework for performing the necessary calculations in a timely manner. For more examples of input-output and IMPLAN related studies please refer to the literature review in Chapter II.

\section{$\underline{\text { IMPLAN }}$}

As part of an efficient approach to quantifying impact estimates, many researchers rely on modeling software. In recent decades, improvements in computer processing have relieved a significant deficit in input-output modeling. Several software packages have been developed for the purpose of constructing models. The impetus behind their creation was the need for tractability in input-output modeling and impact 
analysis. This development was noteworthy because it expedited the process of model development. Prior to this advancement, time considerations for I/O studies were often prohibitive because of the onerous calculations involved. IMPLAN Pro is one example of input-output software available on the market. It is generally accepted as an effective approach to I/O analysis and is frequently used in both academic and government sponsored studies. It is designed to simulate the economic environment based on a user specified study area and to measure the response of the economy to stimuli (Olson and Lindall, 2004). The program was designed to allow the user to easily create and alter the necessary social accounts and multipliers (Olson and Lindall, 2004).

IMPLAN develops I/O models using two basic elements - the software and the database. The software serves as a means for manipulating data and performing calculations based on the study area to develop models. It uses the database components to create social accounting matrices, I/O accounts, and multipliers to create descriptive and predictive models (Olson and Lindall, 2004). IMPLAN also serves as a means of altering regional data based on the unique knowledge of the user with respect to social accounts, multipliers, production functions or trade flows (Olson and Lindall, 2004). Alternatively, it contains default data that can be employed if the user considers the IMPLAN data to be a realistic reflection of their study area (Olson and Lindall, 2004).

\section{IMPLAN Data}

The default data provided by IMPLAN is aggregated from multiple resources and is organized using practices generally accepted by the academic community. The extensive detail available via this medium provides an excellent foundation for model generation. The primary sources of the data are the North American Industrial 
Classification System (NAICS), the Regional Economic Information System (REIS), the Bureau of Labor Statistics and the Bureau of Economic Analysis. For a comprehensive discussion of the IMPLAN data collection process and general methodologies please refer to the IMPLAN Pro User's Guide (Olson and Lindall, 2004).

\section{Primary Data Collection}

IMPLAN, in its most basic form, can be used without additional data collection. However, in the interest of developing an accurate model, primary data on Stanislaus and San Joaquin County fruit and vegetable processors were collected. It was necessary to collect data from the businesses known to rely on the program. The Stanislaus County Department of Environmental Resources (DER) was contacted to identify study candidates. The DER is credited with running the program and enforcing the standards to which it adheres, therefore it has access to much of the proprietary information required for the purposes of this study. Ultimately, ten companies were identified as potential participants in this study based primarily on their residential status.

Once a list of program participants had been populated, a letter was sent out to each company outlining the objectives of the project and requesting company data that would be necessary to run the analysis. This included some private business information including: 1) total output, 2) number of employees and 3) payroll expenses. For a sample of the letter, see Appendix A. A number of factors precluded universal study participation. One of the letters was returned because the establishment had relocated and therefore was no longer a viable participant. Two establishments directly declined to participate due to the sensitive nature of the data requested and five more were unreachable despite repeated attempts to contact via phone and email. Ultimately, only 
two companies were willing to provide all the information necessary. To maintain the anonymity of these companies, they will be referred to only as Processor 1 and Processor 2. Since only two companies provided the necessary information, supplementary information was gathered from the U.S. Census Bureau to use as a proxy for other companies who may be affected. The secondary information collected included statistics for Stanislaus and San Joaquin Counties regarding "fruit and vegetable canning" (NAICS code: 311421$)$. The specific information collected included: number of establishments, total industry output, annual payroll and the number of employees. The data was subsequently used to develop a study area that accurately reflected the local industry.

\section{$\underline{\text { Scenarios Examined Using IMPLAN }}$}

Nine scenarios were analyzed to gauge the potential effect of increasing program costs and the participating food processors vacating their respective county of operation. The first three scenarios were modeled based on a Stanislaus County study area using the data derived from Processor 1's information and average Stanislaus producer statistics provided by the 2002 Economic Census. Processor 1 supplied all the necessary information except revenue, providing instead a range of $\$ 300 \mathrm{M}--\$ 400 \mathrm{M}$. To fully represent this company, two scenarios were run based on its information.

1. Processor $1 \mathrm{~A}(\mathrm{P} 1 \mathrm{~A})-\$ 300 \mathrm{M}$ in output with 1,025 full time equivalents (FTE) - leaves Stanislaus County

2. Processor $1 \mathrm{~B}-\$ 400 \mathrm{M}$ in output with $1,025 \mathrm{FTE}$ - leaves Stanislaus County

Since only two of the prospective participants were willing to provide their proprietary data, an additional scenario was developed for each of the three study areas based on US 
Census Bureau data. The third scenario was based on statistics for Stanislaus County provided by the 2002 U.S. Economic Census.

3. Average fruit and vegetable processor - approximately $\$ 121.5 \mathrm{M}$ in output with 551 FTE - leaves Stanislaus County

The 2002 Census data was used despite partial publication of the 2007 Census because the data relevant to the fruit and vegetable processing industry is not yet publicly available. Processor 2 participates in the program but has its operation in San Joaquin County, so it was not included in this section.

While this project was initially intended to examine the economic impacts that affected Stanislaus County, it was determined that analyzing the information provided by processors located outside the county would be useful in understanding the full impact of the program. The following two scenarios were modeled using a San Joaquin County based study area. The first of these was based on the information provided by Processor 2, a San Joaquin resident.

4. Processor 2 - approximately $\$ 51 \mathrm{M}$ in output with $722 \mathrm{FTE}$ - leaves San Joaquin County

The fifth test was run on the San Joaquin County statistics from the census regarding the fruit and vegetable canning industry.

5. Average fruit and vegetable processor - approximately $\$ 36 \mathrm{M}$ in output with 189 FTE - leaves San Joaquin

The final four scenarios explored the economic impacts in a conflated study area by including both Stanislaus and San Joaquin Counties. This allows for a comprehensive 
view of the program's effects. In this section, the same two tests are run to represent Processor 1.

6. Processor $1 \mathrm{~A}-\$ 300 \mathrm{M}$ in output with $1,025 \mathrm{FTE}$ - leaves the conjugated study area (Stanislaus and San Joaquin Counties)

7. Processor $1 \mathrm{~B}-\$ 400 \mathrm{M}$ in output with $1,025 \mathrm{FTE}-$ leaves the conjugated study area

Because the aggregated study area incorporates both counties, Processor 2's information was also analyzed.

8. Processor $2-$ approx. $\$ 51 \mathrm{M}$ in output with $722 \mathrm{FTE}-$ leaves the conjugated study area

The ninth and final scenario investigated the implications of the average fruit and vegetable processor leaving the conflated study area. This was accomplished by calculating the average revenue and employment for the combined study area.

9. Average fruit and vegetable processor - approximately $\$ 65 \mathrm{M}$ in output with 310 FTE - leaves the conjugated study area

\section{Data Analysis}

To accurately represent each of these scenarios, nine unique models were developed. Each of the economies represented by the models was designed to mirror the specific output per worker and income per worker of the processors represented by each scenario.

IMPLAN expedites the process of model development and provides a simple vehicle for model construction. However, creating a unique study area based on primary data requires a greater understanding of the software and input-output modeling. For 
example, to model an industry upon the data in scenario one, a basic model of Stanislaus County was constructed. The initial model is a reflection of the default data provided by IMPLAN. For the purposes of this research, only data pertaining to "fruit and vegetable canning and drying" - Sector 61 in IMPLAN vernacular - will be altered. The first step in this process is manipulating the primary data so it is correctly formatted for entry in the IMPLAN software.

The following equations illustrate how this is achieved.

$$
\begin{aligned}
& \frac{\text { P1A Total Output }}{\text { P1A Total Employment }}=\text { P1A Output/Worker } \\
& \frac{\text { P1A Total Payroll }}{\text { P1A Total Employment }}
\end{aligned}
$$

The study area must then be altered to reflect the results of these equations.

\section{P1A Output/Worker * Total Employees in Sector $61=$ Total Output in Sector 61 \\ P1A Income/Worker * Total Employees in Sector 61 = Total VA in Sector 61}

The totals obtained for Sector 61, the fruit and vegetable canning and drying industry, are then entered into the regional data. The model is then reconstructed so the multipliers reflect the primary data provided by Processor 1A. This process was replicated for each of the scenarios discussed above.

\section{Multipliers}

As part of the IMPLAN software, the multipliers used in the development of the predictive model were calculated. IMPLAN Pro promotes the use of Type SAM multipliers (Olson and Lindall, 2004). This is the program's default method because it accounts for the greatest number of variables. The approach is based on the data in the social accounting matrices (SAMs). These include the impact of all sources of income, as 
opposed to solely labor income, in the calculation (Olson and Lindall, 2004). Type SAM multipliers encompass the induced effects of the model that are regarded in other multiplier methodologies as a leakage (Olson and Lindall, 2004). In addition to the direct and indirect effect it uses social accounting matrix data to estimate the impacts of interinstitutional transfers (Olson and Lindall, 2004). In this method, households are regarded as separate institutions. Type SAM multipliers incorporate other final demand institutions (federal, state, and local government agencies, for example) (Olson and Lindall, 2004). Given the comprehensive nature of the Type SAM multiplier, it was the best option for model construction. For an in-depth discussion of multipliers, see Olson and Lindall's IMPLAN Pro User's Guide.

\section{Impact Analysis}

Once the study area has been altered to reflect the processor data and multipliers have been constructed, an impact analysis is run. Economic impact analysis is the process in which a final demand change is applied to the predictive model, which generates results through multipliers that reflect changes in output, value-added and employment in the region (Olson and Lindall, 2004). These changes can include a variety of economic stimuli. For the purposes of this study, the impacts revolve around changes in the fruit processing industry. This may be relevant for governments with respect to policy decisions and planning.

Impact analysis equates an economic stimulus with the involved firms and individuals (Olson and Lindall, 2004). These economic issues can then be transformed into expenditures that represent the direct effects of economic modeling (Olson and Lindall, 2004). The iterative effects they catalyze are the indirect and induced effects. 
For the purposes of this research, one impact was run in each model. This impact represented the consequences of the processor leaving the county. For example, in the model founded upon the data provided by Processor 1A an impact analysis was run under the guise of Processor 1A exiting the county.

\section{Sensitivity Analysis}

Each of the primary analyses was run using model-developed RPCs that are specific to the study area. These were created through a set of econometrically-based equations using the IMPLAN data. For this study area, the average RPC for the industry was decidedly low. In the interest of fully analyzing the issue, secondary analyses were run as a sensitivity analysis using the default assumption that $100 \%$ of the inputs for these operations was purchased locally, indicating an RPC of 1.0. The processors surveyed insinuated that this was a reasonable postulation. Given the wide range of RPCs, the sensitivity analysis provided a wide range of possible values.

\section{$\underline{\text { Inflation Adjustment }}$}

The results provided by the primary and sensitivity analyses were based on 2004 data provided by IMPLAN. At the time of project inception this was the most current data available. To make the study more pertinent, the results were converted into 2009 dollars using the US Bureau of Labor Statistic's inflation calculator. The calculator uses the average Consumer Price Index for each calendar year. The data used in the calculations represents the fluctuating prices of all goods and services. The index has assimilated price data for every year since 1913 (“C.P.I. Inflation Calculator”). The 
adjustments made using this calculator are the reason the results in Chapter V do not match the original IMPLAN results.

\section{Limitations to the Analysis}

One of the primary limitations of IMPLAN needs to be addressed before considering the results. IMPLAN as it is used in this study does not take into account any firm or industry that may fill the gap if an establishment chooses to leave Stanislaus County. In a sense, IMPLAN is only being used to investigate the initial effect of a change in the basic nature of the food processing industry. It is possible that another industry and/or firm may enter into the county to absorb some of the negative impact that may occur due to the processor exiting. No attempt was made in this study to examine what industries may fill the gap if a processor decided to leave.

Another limitation to this study is that the processors who participated in this study provided information that could not be directly verified by the researchers for this project. To address this challenge, scenarios 3,5 and 9 were developed to take into consideration average producers in the industry who may use the Stanislaus County Food Processing Byproduct Use Program.

Lastly, this study did not to assess the probability that any processor would leave or what specific conditions would make the processor exit the county. This study examined the short term economic impact of one processor leaving. 


\section{CHAPTER V:}

\section{RESULTS}

\section{Introduction}

This chapter presents the results of the IMPLAN analyses. Each of the nine scenarios is reviewed based on its direct, indirect, and induced effects and their implications for output, value-added, employment and tax revenues. These are followed by a discussion of the numbers generated by the sensitivity analysis.

Using IMPLAN, it is estimated that Stanislaus County had a total output of $\$ 27.48 \mathrm{~B}$ in 2004 which inflates to $\$ 31.42 \mathrm{~B}$ in 2009 dollars. It is estimated that the fruit canning and drying industry provided $\$ 1.8 \mathrm{~B}$ to the economy in 2004 which equals $\$ 2.1 \mathrm{~B}$ in 2009 dollars. This implies that the industry contributed approximately $6.7 \%$ of the total Stanislaus County economic output.

San Joaquin County has a slightly larger total output of $\$ 32.7 \mathrm{~B}$, or $\$ 37.4 \mathrm{~B}$ when adjusted for inflation. However, the fruit canning and drying industry comprises a lesser fraction of the economy as a whole, $\$ 623.4 \mathrm{M}$, or $\$ 712.7 \mathrm{M}$ after inflation. The industry represents only $1.9 \%$ of the county's total output without considering the indirect or induced effects. Given these metrics, it is clear that the fruit and vegetable canning and drying industry is not as thoroughly integrated in the San Joaquin economy and therefore, the county is less reliant on the industry than Stanislaus, which will lessen the impact of the loss of program viability. 


\section{Output Impacts}

Table 5-1 reveals the estimated economic impact on total output for the nine scenarios referenced in Chapter IV. All of the impacts are in 2009 dollars. This table shows that if Processor 1 did not considered the program to be viable and chose to exit the county due to competitive losses, the county should expect to lose $\$ 350.3 \mathrm{M}-$ $\$ 467.6 \mathrm{M}$ in total economic output. As a fraction of industry output this represents a $25 \%$ loss. Approximately $98 \%$ results from the direct effect of the firm no longer operating in Stanislaus. This is an extremely large percentage, indicating that the Stanislaus County fruit and vegetable canning industry has a very low overall RPC. The remaining $2 \%$ of the loss will affect other industries, government and local households through indirect and induced effects. These indicate that the loss of one fruit processor will not be felt significantly beyond the primary industry.

When San Joaquin County is incorporated into the study area, the results are only slightly higher. Considering a region composed of both counties, the loss of Processor 1 results in an output loss of $\$ 352.2 \mathrm{M}$ - $\$ 470 \mathrm{M}$. Processor 2 is estimated to have a total effect on the region (i.e. Stanislaus and San Joaquin County) of \$59.1M. The majority of the impact resulting from the loss of this establishment is felt by San Joaquin County. Ninety-nine percent of the total impact results from the processor leaving, while only $1 \%$ will affect local supporting industries, governments and households. Examining Processor 2 reveals that Stanislaus County is not the only county that will be impacted by the program's loss of viability, but the effect is primarily in the directly affected fruit and vegetable processing industry. 
Table 5-1: Potential Output Losses Based on Model RPCs (2009 Dollars)

\begin{tabular}{|c|c|c|c|c|c|}
\hline & Scenario & Direct & Indirect & Induced & Total $*$ \\
\hline \multirow{3}{*}{ 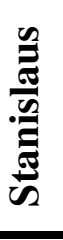 } & Processor 1A & $\$ 342,989,412$ & $\$ 5,265,210$ & $\$ 2,006,848$ & $\$ 350,261,470$ \\
\hline & Processor 1B & $\$ 457,319,216$ & $\$ 7,554,655$ & $\$ 2,489,463$ & $\$ 467,363,334$ \\
\hline & $\begin{array}{l}\text { Average Fruit and } \\
\text { Vegetable Processors } \\
\end{array}$ & $\$ 138,864,801$ & $\$ 1,859,573$ & $\$ 887,093$ & $\$ 141,611,467$ \\
\hline \multirow[b]{2}{*}{$\overrightarrow{0}$} & Processor 2 & $\$ 58,607,281$ & $\$ 231,775$ & $\$ 245,133$ & $\$ 59,084,189$ \\
\hline & $\begin{array}{l}\text { Average Fruit and } \\
\text { Vegetable Processors } \\
\end{array}$ & $\$ 41,582,667$ & $\$ 323,663$ & $\$ 184,641$ & $\$ 42,090,971$ \\
\hline \multirow{4}{*}{ है } & Processor 1A & $\$ 342,989,412$ & $\$ 6,558,154$ & $\$ 2,626,413$ & $\$ 352,173,979$ \\
\hline & Processor 1B & $\$ 457,319,216$ & $\$ 9,407,898$ & $\$ 3,281,136$ & $\$ 470,008,250$ \\
\hline & Processor 2 & $\$ 58,607,284$ & $\$ 241,449$ & $\$ 454,192$ & $\$ 59,302,925$ \\
\hline & $\begin{array}{l}\text { Average Fruit and } \\
\text { Vegetable Processors }\end{array}$ & $\$ 74,085,806$ & $\$ 1,183,877$ & $\$ 632,145$ & $\$ 75,901,828$ \\
\hline
\end{tabular}

* Totals may not sum to direct, indirect, and induced due to rounding errors. 
The average Stanislaus fruit and vegetable processor (based on the information provided by the 2002 Economic Census) falls in between Processors 1 and 2. It is estimated that the county of Stanislaus would lose a total of $\$ 141.6 \mathrm{M}$ in economic activity from the loss of the average processor. Again, the vast majority of this is the direct effect of the impact in the primary industry, $\$ 138.9 \mathrm{M}$. Only $2 \%$ of this impact, i.e., $\$ 2.7 \mathrm{M}$, will be felt by households, government, and supporting industries through indirect and induced effects. Again, these are very small numbers because the industry in this region has low RPCs.

In contrast, the average fruit and vegetable processor in San Joaquin County tends to be much smaller than those in Stanislaus County because the industry is less prolific. Were the average processor to leave the county it would suffer a $\$ 42.1 \mathrm{M}$ loss in economic output, which almost solely represents the direct effects of the impact.

\section{Output Sensitivity Analysis}

The sensitivity analysis illustrates the influence regional purchase coefficients have in multiplier development. Choosing a higher RPC - 100\% in this case significantly increases the effects of an economic stimulus. This is exemplified in Scenario 1 in which Processor 1A leaves Stanislaus County. In the initial analysis where the model-developed RPC is used, the total impact is $\$ 350.3 \mathrm{M}$. By comparison, an analysis run on the same scenario using an RPC of $100 \%$ yields a total of $\$ 540.1 \mathrm{M}$. The direct effect of this analysis accounts for only $63.5 \%$ of the total. In the complete output sensitivity analysis, the value of the direct impact as a percent of the total ranged from $45.7 \%$ to $81 \%$. 
Table 5-2: Sensitivity Analysis - Potential Output Losses Based on 100\% RPC (2009 Dollars)

\begin{tabular}{|c|c|c|c|c|c|}
\hline & Scenario & Direct & Indirect & Induced & Total* \\
\hline \multirow{3}{*}{ 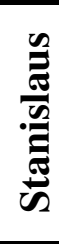 } & Processor 1A & $\$ 342,989,412$ & $\$ 142,691,776$ & $\$ 54,387,328$ & $\$ 540,068,516$ \\
\hline & Processor 1B & $\$ 457,319,216$ & $\$ 204,737,729$ & $\$ 67,466,624$ & $\$ 729,523,570$ \\
\hline & $\begin{array}{l}\text { Average Fruit and } \\
\text { Vegetable Processors }\end{array}$ & $\$ 138,864,797$ & $\$ 50,784,430$ & $\$ 24,226,268$ & $\$ 213,875,495$ \\
\hline \multirow[b]{2}{*}{$\overrightarrow{5}$} & Processor 2 & $\$ 58,607,282$ & $\$ 9,089,162$ & $\$ 9,613,018$ & $\$ 77,309,462$ \\
\hline & $\begin{array}{l}\text { Average Fruit and } \\
\text { Vegetable Processors }\end{array}$ & $\$ 42,153,787$ & $\$ 14,925,910$ & $\$ 8,514,846$ & $\$ 65,594,544$ \\
\hline \multirow{4}{*}{ ڤ艹 } & Processor 1A & $\$ 342,989,412$ & $\$ 150,279,008$ & $\$ 60,183,893$ & $\$ 553,452,312$ \\
\hline & Processor 1B & $\$ 457,319,216$ & $\$ 215,580,728$ & $\$ 75,186,755$ & $\$ 748,086,698$ \\
\hline & Processor 2 & $\$ 58,607,287$ & $\$ 4,785,568$ & $\$ 9,002,180$ & $\$ 72,395,035$ \\
\hline & $\begin{array}{l}\text { Average Fruit and } \\
\text { Vegetable Processors }\end{array}$ & $\$ 74,085,804$ & $\$ 73,272,001$ & $\$ 14,705,360$ & $\$ 162,063,166$ \\
\hline
\end{tabular}

* Totals may not sum to direct, indirect, and induced due to rounding errors. 
This presents a distinct contrast when compared to the primary analysis. The average for the primary scenarios was approximately $98 \%$, indicating the indirect and induced effects in the sensitivity analysis are much greater. Again using Processor $1 \mathrm{~A}$ as an example, the indirect and induced effects of the primary analyses are $\$ 5.3 \mathrm{M}$ and $\$ 2 \mathrm{M}$, respectively. The sensitivity analysis establishes the variables at $\$ 142.7 \mathrm{M}$ and $\$ 54.4 \mathrm{M}$, indicating that there is minimal change in the direct impact, while the changes in the indirect and induced impacts are significant.

\section{$\underline{\text { Value-Added Impacts }}$}

An additional measure of economic activity is value-added, which is a reflection of employee compensation, proprietor income, other property income and indirect business taxes. It is estimated that in 2009 Stanislaus County and San Joaquin County have a total value-added of $\$ 16.1 \mathrm{~B}$ and $\$ 20.4 \mathrm{~B}$, respectively. This total value-added equates to $51 \%$ of the total output generated in the Stanislaus economy. The fruit canning and drying industry represents $\$ 485.1 \mathrm{M}$ of this value-added in terms of 2009 dollars.

Table 5-2 presents the estimated losses in value-added that would transpire if the Stanislaus County Food Processing Byproduct Use Program was not a viable option. Examining this table shows that if Processor 1 chose to leave Stanislaus County due to program alterations, the county would lose approximately $\$ 7.6-\$ 9.1 \mathrm{M}$ in value-added economic activity. The direct effect would be $\$ 3.5 \mathrm{M}$ under either scenario because the payroll is constant. The difference in the upper and lower estimate occurs as a result of the indirect and induced effects that occur because of the changes in revenue. 
Table 5-3: Potential Value-Added Losses Based on Model RPCs (2009 Dollars)

\begin{tabular}{|c|c|c|c|c|c|}
\hline & Scenario & Direct & Indirect & Induced & Total* \\
\hline \multirow{3}{*}{ 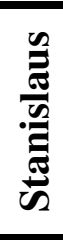 } & Processor 1A & $\$ 3,540,912$ & $\$ 2,846,489$ & $\$ 1,221,912$ & $\$ 7,609,313$ \\
\hline & Processor 1B & $\$ 3,540,923$ & $\$ 4,074,318$ & $\$ 1,515,459$ & $\$ 9,130,700$ \\
\hline & $\begin{array}{l}\text { Average Fruit and } \\
\text { Vegetable Processors }\end{array}$ & $\$ 1,917,877$ & $\$ 1,007,391$ & $\$ 540,236$ & $\$ 3,465,504$ \\
\hline \multirow[b]{2}{*}{$\vec{E}$} & Processor 2 & $\$ 1,100,454$ & $\$ 129,192$ & $\$ 148,436$ & $\$ 1,378,082$ \\
\hline & $\begin{array}{l}\text { Average Fruit and } \\
\text { Vegetable Processors }\end{array}$ & $\$ 344,842$ & $\$ 180,489$ & $\$ 111,809$ & $\$ 637,140$ \\
\hline \multirow{4}{*}{ 至 } & Processor 1A & $\$ 4,013,368$ & $\$ 3,575,614$ & $\$ 1,585,093$ & $\$ 9,174,075$ \\
\hline & Processor 1B & $\$ 4,013,368$ & $\$ 5,124,372$ & $\$ 1,980,427$ & $\$ 11,118,167$ \\
\hline & Processor 2 & $\$ 2,569,099$ & $\$ 132,256$ & $\$ 274,105$ & $\$ 2,975,460$ \\
\hline & $\begin{array}{l}\text { Average Fruit and } \\
\text { Vegetable Processors }\end{array}$ & $\$ 1,235,044$ & $\$ 646,260$ & $\$ 381,494$ & $\$ 2,262,798$ \\
\hline
\end{tabular}

* Totals may not sum to direct, indirect, and induced due to rounding errors. 
Were Processor 2 to leave San Joaquin County because of alterations in the Stanislaus County Food Processing Byproduct Use Program, San Joaquin could expect to lose $\$ 1.4 \mathrm{M}$ in value-added activity which includes employee compensation, proprietary income, other property type income and indirect business taxes. This stems from a loss of $\$ 1.1 \mathrm{M}$ in direct effects and $\$ 277 \mathrm{~K}$ in indirect and induced effects.

If the average fruit and vegetable processor left Stanislaus County, it would result in an anticipated loss of $\$ 3.5 \mathrm{M}$ in value-added activity. This loss is based on a $\$ 1.92 \mathrm{M}$ direct effect, a $\$ 1 \mathrm{M}$ indirect effect, and a $\$ 540 \mathrm{~K}$ induced effect, nearly $56 \%$ results from direct effects, while the balance occurs due to indirect and induced effects.

\section{Value-Added Sensitivity Analysis}

The distribution of value-added benefits is unchanged by the sensitivity analysis. However, the IMPLAN appraisal of these values estimated that they increase by a factor of at least twenty. This was true across all areas: direct, indirect and induced effects. Indicating that in the scenarios run as part of the primary analysis, a large fraction of the workers resided outside of the County. The sensitivity analysis mandates that all the employees be local, which explains the considerable increase in value, as much as \$243.7M for Processor 1B. 
Table 5-4: Sensitivity Analysis - Potential Value-Added Losses Based on 100\% RPC (2009 Dollars)

\begin{tabular}{|c|c|c|c|c|c|}
\hline & Scenario & Direct & Indirect & Induced & Total* \\
\hline \multirow{3}{*}{ 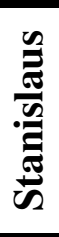 } & Processor 1A & $\$ 3,540,912$ & $\$ 2,846,489$ & $\$ 1,221,912$ & $\$ 7,609,313$ \\
\hline & Processor 1B & $\$ 3,540,923$ & $\$ 4,074,318$ & $\$ 1,515,459$ & $\$ 9,130,700$ \\
\hline & $\begin{array}{l}\text { Average Fruit and } \\
\text { Vegetable Processors }\end{array}$ & $\$ 1,917,877$ & $\$ 1,007,391$ & $\$ 540,236$ & $\$ 3,465,504$ \\
\hline \multirow[b]{2}{*}{$\vec{\nabla}$} & \begin{tabular}{|l} 
Processor 2 \\
\end{tabular} & $\$ 1,100,454$ & $\$ 129,192$ & $\$ 148,436$ & $\$ 1,378,082$ \\
\hline & $\begin{array}{l}\text { Average Fruit and } \\
\text { Vegetable Processors }\end{array}$ & $\$ 344,842$ & $\$ 180,489$ & $\$ 111,809$ & $\$ 637,140$ \\
\hline \multirow{4}{*}{ ڤึ } & Processor 1A & $\$ 4,013,368$ & $\$ 3,575,614$ & $\$ 1,585,093$ & $\$ 9,174,075$ \\
\hline & Processor 1B & $\$ 4,013,368$ & $\$ 5,124,372$ & $\$ 1,980,427$ & $\$ 11,118,167$ \\
\hline & Processor 2 & $\$ 2,569,099$ & $\$ 132,256$ & $\$ 274,105$ & $\$ 2,975,460$ \\
\hline & $\begin{array}{l}\text { Average Fruit and } \\
\text { Vegetable Processors }\end{array}$ & $\$ 1,235,044$ & $\$ 646,260$ & $\$ 381,494$ & $\$ 2,262,798$ \\
\hline
\end{tabular}

\footnotetext{
* Totals may not sum to direct, indirect, and induced due to rounding errors.
} 


\section{$\underline{\text { Tax Revenue Impacts }}$}

Table 5-3 provides a view of tax revenue impacts if any of the scenarios put forth in this study came to fruition. To interpret the results from this table the reader should understand that these results are predicated upon the processor going out of business or moving their operations out of the study area. In the primary analysis, if the processor decided to leave Stanislaus and moved to another county in California, the federal government would lose very little and state tax dollars would remain roughly the same. Only the local county taxes would be significantly impacted by the processor's departure.

The tax impact of Processor 1 leaving the county would be $\$ 1.9 \mathrm{M}-\$ 2.3 \mathrm{M}$ for local, state and federal government. The state and local government should expect to receive $45 \%$ of this total tax revenue. The average processor however, generates significantly less revenue, $\$ 823 \mathrm{~K}$ with $\$ 363 \mathrm{~K}$ going to state and local tax coffers.

If Processor 2 chose to leave San Joaquin, it is estimated that local, state and federal government would lose $\$ 297 \mathrm{~K}$ in tax revenue where the state and local government receive $43 \%$ of this total. The average fruit and vegetable processor in the county has a similar tax impact of $\$ 155 \mathrm{~K}$. These numbers are not material by government standards so changes of this nature are not likely the result in major tax implications. 
Table 5-5: Potential Revenue Tax Losses Based on Model RPCs (2009 Dollars)

\begin{tabular}{|c|c|c|c|c|}
\hline & Scenario & Federal & State/Local & Total \\
\hline \multirow{3}{*}{ 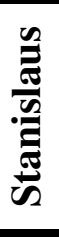 } & Processor 1A & $\$ 1,021,917$ & $\$ 825,780$ & $\$ 1,847,697$ \\
\hline & \begin{tabular}{|l|} 
Processor 1B \\
\end{tabular} & $\$ 1,241,635$ & $\$ 1,016,692$ & $\$ 2,258,327$ \\
\hline & $\begin{array}{l}\text { Average Fruit and } \\
\text { Vegetable Processors }\end{array}$ & $\$ 460,733$ & $\$ 363,137$ & $\$ 823,870$ \\
\hline \multirow[b]{2}{*}{$\vec{\sim}$} & \begin{tabular}{|l} 
Processor 2 \\
\end{tabular} & $\$ 158,561$ & $\$ 138,742$ & $\$ 297,303$ \\
\hline & $\begin{array}{l}\text { Average Fruit and } \\
\text { Vegetable Processors }\end{array}$ & $\$ 88,809$ & $\$ 66,751$ & $\$ 155,560$ \\
\hline \multirow{4}{*}{ 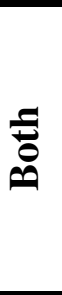 } & Processor 1A & $\$ 1,246,189$ & $\$ 1,013,746$ & $\$ 2,259,935$ \\
\hline & Processor 1B & $\$ 1,528,010$ & $\$ 1,262,778$ & $\$ 2,790,788$ \\
\hline & Processor 2 & $\$ 323,130$ & $\$ 295,421$ & $\$ 618,551$ \\
\hline & $\begin{array}{l}\text { Average Fruit and } \\
\text { Vegetable Processors }\end{array}$ & $\$ 305,102$ & $\$ 238,273$ & $\$ 543,375$ \\
\hline
\end{tabular}

* Totals may not sum to direct, indirect, and induced due to a transfer that occurs from the government to the processor. 
When the two counties are aggregated to create a comprehensive study area it provides a complete view of the tax implications of changes in the industry. In this scenario, if Processor 1 were to leave, the two counties would lose $\$ 2.3 \mathrm{M}-\$ 2.8 \mathrm{M}$. Again, approximately $45 \%$ of this tax revenue is conveyed to state and local government. Given that Processor 2 is a significantly smaller establishment, it is reasonable that it would generate less in tax revenue. This company paid a total of $\$ 618 \mathrm{~K}$ in taxes, $\$ 295 \mathrm{~K}$ of which is state and local revenue. Finally, the average processor in the region falls in between Processor 1 and Processor 2 with $\$ 543 \mathrm{~K}$ in tax revenue.

\section{Tax Sensitivity Analysis}

The sensitivity analysis revealed material fiscal implications with respect to taxes. In each set of analyses, state and local taxes accounted for slightly less than half (45\%) of the revenue generated in each scenario. While the percentage may be static, the numeric value of the taxes changed significantly. For example, in the sensitivity analysis Processor 1 represents a total change in revenue of $\$ 48.2 \mathrm{M}-\$ 58.9 \mathrm{M}$. In contrast, Processor 2 generates less income and therefore pays less in business taxes. However, the sensitivity analysis results in a tax increase of $\$ 21.7 \mathrm{M}$. Again, these numbers are evidence of the importance of RPCs in multiplier development and therefore impact analysis. 
Table 5-6: Sensitivity Analysis - Potential Tax Revenue Losses Based on 100\% RPC (2009 Dollars)

\begin{tabular}{|c|c|c|c|c|}
\hline & Scenario & Federal & State/Local & Total \\
\hline \multirow{3}{*}{ 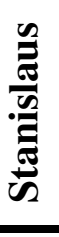 } & Processor 1A & $\$ 27,694,871$ & $\$ 22,379,369$ & $\$ 50,074,240$ \\
\hline & \begin{tabular}{|l|} 
Processor 1B \\
\end{tabular} & $\$ 33,649,391$ & $\$ 27,553,245$ & $\$ 61,202,636$ \\
\hline & $\begin{array}{l}\text { Average Fruit and } \\
\text { Vegetable Processors }\end{array}$ & $\$ 12,582,482$ & $\$ 9,917,191$ & $\$ 22,499,673$ \\
\hline \multirow[b]{2}{*}{ ज } & \begin{tabular}{|l|} 
Processor 2 \\
\end{tabular} & $\$ 6,218,087$ & $\$ 5,440,840$ & $\$ 11,658,927$ \\
\hline & $\begin{array}{l}\text { Average Fruit and } \\
\text { Vegetable Processors }\end{array}$ & $\$ 4,095,483$ & $\$ 3,078,272$ & $\$ 7,173,755$ \\
\hline \multirow{4}{*}{ صี } & Processor 1A & $\$ 28,556,241$ & $\$ 23,229,845$ & $\$ 51,786,086$ \\
\hline & \begin{tabular}{|l|} 
Processor 1B \\
\end{tabular} & $\$ 35,014,142$ & $\$ 28,936,375$ & $\$ 63,950,516$ \\
\hline & \begin{tabular}{|l} 
Processor 2 \\
\end{tabular} & $\$ 6,404,505$ & $\$ 5,855,293$ & $\$ 12,259,799$ \\
\hline & $\begin{array}{l}\text { Average Fruit and } \\
\text { Vegetable Processors }\end{array}$ & $\$ 7,097,481$ & $\$ 5,542,856$ & $\$ 12,640,337$ \\
\hline
\end{tabular}

* Totals may not sum to direct, indirect, and induced due to a transfer that occurs from the government to the processor. 


\section{Employment Impacts}

This report has focused on the financial impact that would be felt by the local economy if a particular food processor went out of business due to a change in the Stanislaus County Food Processing Byproduct Use Program. All of the impacts to the local economy have been measured in 2009 dollars. IMPLAN allows for one other critical impact to be estimated — the loss of employment opportunities. Based on IMPLAN estimates, there were 4,287 workers who relied on the fruit and vegetable canning and drying industry for employment in 2004.

Table 5-4 reflects the estimated job loss if a processor left its respective county. It is estimated that if Processor 1 left Stanislaus the county could expect a loss of 87 -105 jobs. Since over half of these jobs result from indirect and induced effects the loss of employment would impact employees in supporting industries more than the employees who work for Processor 1. However, these are not likely to be typical results. The average fruit and vegetable processor leaving Stanislaus County will result in a loss of 39 jobs, significantly less than Processor 1.

Processor 2 also elicits lesser impacts than Processor 1. More than half of the 22 job losses that would occur in San Joaquin County would impact employees working for Processor 2. Only $43 \%$ of the total job losses would affect employees in supporting industries. The job loss incurred from average San Joaquin fruit and vegetable processor vacating the county is estimated to be 8 jobs. The probable reason this number is so low is because a large portion of the company's employees are in-commuters (i.e. people who commute to their job from outside of the study area). Many of these jobs (47\%) would come from supporting industries. 
Table 5-7: Potential Job Losses Based on Model RPC*

\begin{tabular}{|c|c|c|c|c|c|}
\hline & Scenario & Direct & Indirect & Induced & Total $* *$ \\
\hline \multirow{3}{*}{ 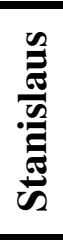 } & Processor 1A & 37.8 & 31.8 & 17.7 & 87.3 \\
\hline & Processor 1B & 37.8 & 45.6 & 21.9 & 105.3 \\
\hline & $\begin{array}{l}\text { Average Fruit and } \\
\text { Vegetable Processors }\end{array}$ & 20.2 & 11.2 & 7.8 & 39.2 \\
\hline \multirow[b]{2}{*}{$\overrightarrow{0}$} & Processor 2 & 18.4 & 1.4 & 2.1 & 21.9 \\
\hline & $\begin{array}{l}\text { Average Fruit and } \\
\text { Vegetable Processors }\end{array}$ & 4.1 & 2.0 & 1.6 & 7.7 \\
\hline \multirow{4}{*}{ ڤ艹 } & Processor 1A & 44.7 & 39.7 & 22.5 & 106.9 \\
\hline & Processor 1B & 44.7 & 57.0 & 28.1 & 129.8 \\
\hline & Processor 2 & 36.4 & 1.5 & 3.9 & 41.8 \\
\hline & $\begin{array}{l}\text { Average Fruit and } \\
\text { Vegetable Processors }\end{array}$ & 13.3 & 7.2 & 5.4 & 25.9 \\
\hline
\end{tabular}

*Job numbers are in terms of 2004 values.

** Totals may not sum to direct, indirect, and induced due to rounding errors. 
In the conjugated study area the loss of Processor 1 would result in job losses of $107-130$ jobs. An average of $63 \%$ of these positions would be lost in industries supporting the fruit and vegetable processing industry. As a smaller company, Processor 2 leaving the study area, Stanislaus and San Joaquin Counties results in a total loss of 42 jobs. However, in this scenario the majority of the job losses (87\%) are in the primary industry. Lastly, when the average fruit and vegetable processor statistics from the two counties are aggregated and counted as a loss, the total loss is 26 jobs.

\section{Employment Sensitivity Analysis}

Employment proved to be one of the most responsive economic indicators. Changes made in the sensitivity analysis had significant ramifications for the number of local workers. In the primary analyses only a small fraction of the employees (3.7\%) resided within the study area. Direct effects range from a low of 35.9\% for Processor 1B to a high of $87.2 \%$ for Processor 2 . The differences in this statistic are a symptom of the changes made to the study area discussed in the methodology. Similar to the other sensitivity analyses, the ratio of direct, indirect and induced effects remains the same. However, the sensitivity analysis increased direct, indirect, and induced employment numbers by as much as 980 workers, 1,248 workers, and 616 workers respectively. 
Table 5-8: Sensitivity Analysis - Potential Job Losses Based on 100\% RPC*

\begin{tabular}{|c|c|c|c|c|c|}
\hline & Scenario & Direct & Indirect & Induced & Total $* *$ \\
\hline \multirow{3}{*}{ 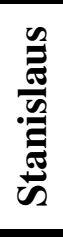 } & Processor 1A & $1,025.0$ & 861.3 & 478.3 & $2,364.6$ \\
\hline & \begin{tabular}{|l|} 
Processor 1B \\
\end{tabular} & $1,025.0$ & $1,236.0$ & 593.8 & $2,854.8$ \\
\hline & $\begin{array}{l}\text { Average Fruit and } \\
\text { Vegetable Processors }\end{array}$ & 551.0 & 306.4 & 212.9 & $1,070.3$ \\
\hline \multirow[b]{2}{*}{$\overrightarrow{\sigma^{2}}$} & \begin{tabular}{|l|l} 
Processor 2 \\
\end{tabular} & 722.0 & 56.7 & 82.3 & 861.0 \\
\hline & $\begin{array}{l}\text { Average Fruit and } \\
\text { Vegetable Processors }\end{array}$ & 189.0 & 93.0 & 72.9 & 354.9 \\
\hline \multirow{4}{*}{ 䒿 } & Processor 1A & $1,025.0$ & 909.3 & 515.3 & $2,449.6$ \\
\hline & Processor 1B & $1,025.0$ & $1,305.1$ & 644.2 & $2,974.3$ \\
\hline & Processor 2 & 722.0 & 29.1 & 77.0 & 828.1 \\
\hline & $\begin{array}{l}\text { Average Fruit and } \\
\text { Vegetable Processors }\end{array}$ & 310.0 & 166.6 & 125.8 & 602.4 \\
\hline
\end{tabular}

*Job numbers are in terms of 2004 values.

** Totals may not sum to direct, indirect, and induced due to rounding errors. 


\section{$\underline{\text { Affected Industries }}$}

As a significant component of the regional economy, the fruit and vegetable processing industry stimulates activity in numerous sectors. As a result, changes in its composition catalyze effects that reverberated throughout the county. Some of the most susceptible industries include: wholesale trade, truck transportation, vegetable and melon farming, management of companies and enterprises and metal container manufacturing. These industries were especially affected with respect to output, vacillating by as much as $\$ 26 \mathrm{M}$. This is largely because these are the industries whose output is most closely correlated with the health of the fruit and vegetable processing industry.

Changes in value-added generated a slightly different list. Industries with the greatest sensitivity were wholesale trade, vegetable and melon farming, owner-occupied dwellings, management of companies and enterprises and truck transportation. Wholesale trade suffered an $\$ 18 \mathrm{M}$ loss in value-added as a result of a $\$ 300 \mathrm{M}$ output loss in fruit and vegetable processing, indicating a high degree of dependency.

Lastly, employment proved to be an effective indicator of economic linkages. Again, the most vulnerable industry is wholesale trade, followed by food services and drinking places, truck transportation, management of companies and enterprises and fruit farming. Each of these industries was appreciably affected, however, employment effects proved to be relatively well dispersed. The most highly affected industry (wholesale trade) suffered a loss of 188 out of 2,449 jobs. The losses in other industries decreased from there, with the average job losses being around 10. While there is some variability in the most highly affected industries, this study clarifies which are most likely to be susceptible to a contraction of the food processing industry. 


\section{CHAPTER VI:}

\section{SUMMARY AND CONCLUSIONS}

\section{Introduction}

This report highlighted the economic consequences if changes in the Stanislaus County Food Processing Byproduct Use Program precluded further food processor involvement. The program has proven to be an asset to the local agricultural community and has been a vital component of the food processing industry since its inception. It provides a mechanism for allocating byproducts to other avenues where it would be used as a feed additive or as a soil amendment. Unfortunately, the RWQCB has expressed apprehension regarding its implications for water quality. Under threat of the losing the program, certain operations have asserted that they may have to leave the county to recover their competitive losses. This research serves to valuate the food processing industry - particularly fruit and vegetable canning - and thereby determine the economic value of the program. Data was collected from two processors that currently use the program as an integral part of their disposal practices. This data was used to develop six scenarios that reflected the circumstances if the processors were to leave their county of residence. Another three scenarios were constructed based on average processor data provided by the 2002 US Census. These scenarios were analyzed using IMPLAN which provided results regarding four economic indicators - output, value-added, taxes, and employment. 


\section{Results and Implications}

The results between the primary analysis and the sensitivity analysis varied considerably as a result of differences in the RPCs. The primary analysis illustrated that if Processor 1 left Stanislaus County the implications would be relatively minimal beyond the direct output impacts. It is estimated that the county could expect to see a loss of $\$ 350.3 \mathrm{M}-\$ 467.4 \mathrm{M}$ in total economic output. Approximately $98 \%$ of the output loss in the primary analysis is the result of the direct effect of the processor leaving (inflated to 2009 dollars). However, the sensitivity analysis suggests that output losses could be as high as $\$ 729.5 \mathrm{M}$. This variation is evident in all the analyses and economic indicators. This is especially evident with respect to job losses, which are often of particular interest to policy-makers. The primary analysis for Processor 1 estimated job losses to be in the range of $87-105$ jobs, the majority of this will be felt by the primary industry. However, the sensitivity analysis yields a much higher range of results $-2,364-2,854$ jobs.

Given the absence of specific data regarding RPCs, it is difficult to determine which of the analyses is more accurate. Under the circumstances, any attempt to hypothesize as to the exact value of the RPCs would be speculation. It seems reasonable that the value of the processors lies somewhere in the middle, probably closer to the low end of the spectrum considering the size of the study area. The only likely exception is employment. It is likely that the RPC specific to this input is actually higher than IMPLAN estimated because many of the processor's employees are likely to reside in the county in which they work.

While the scenarios in the primary and sensitivity analyses vary significantly, both suggest that Stanislaus and San Joaquin Counties have a vested interest in ensuring 
that the Stanislaus County Food Processing Byproduct Use Program remains a viable disposal option for processors.

\section{Opportunities for Further Research}

This project has illuminated other areas that require additional research. The cardinal insufficiency is the lack of primary data regarding regional purchase coefficients. RPCs are one of the most important factors in multiplier development because they provide the fraction of an industry's inputs that are purchased locally. Therefore, they are very influential in determining the results of a study. Further research in this segment would provide more specific data regarding the economic contributions of the industry.

Additionally, continued research to identify the opportunity costs of the fruit and vegetable processing industry's inputs would be useful. For every input involved in a project, activity or event, there is an opportunity cost. Realistically estimating the value of these forsaken earnings can be problematic. Many studies assume full resource employment, perfect resource mobility and an absence of scale economies (Hamilton et al., 1991). However, under these circumstances, the factor benefit would be zero because all inputs could produce the same pecuniary benefit under alternative employment. "In other words, the income impact resulting from other project-related activity is exactly offset by the opportunity cost of the resources used" (Hamilton et al., 1991, p. 335). To address this issue, most analyses assume that at least one primary input is unemployed/ underemployed and immobile. This distinction results in a low opportunity cost for that resource and effectively increases the direct net benefits of the project (Hamilton et al., 1991). 
There has been minimal empirical analysis to indicate the degree of resource utilization. Therefore, regional input-output analysis relies primarily on assumptions of resource employment. Very little empirical work has been done to establish realistic estimates of input use (Hamilton et al., 1991). Most studies attempting to address the issue draw many of their conclusions from assumptions. This void in the literature is an opportunity for continued study. 


\section{WORKS CITED}

"Action Agenda Summary, Board Agenda \# B-19". 2006. Ed. Stanislaus County Board of Supervisors. August 10, 2007. <http://www.co.stanislaus.ca.us/>.

Almon, C. "Investment in Input-Output Models and the Treatment of Secondary Products. "Applications of Input-Output Analysis. Eds. A.P. Carter and A. Brody. Amsterdam, Holland, 1970.

---. "Product-to-Product Table Via Product-Technology with No Negative Flows." Economic Systems Research 12 (2000): 27-43.

Archibald, Sandra O., Alex F. McCalla, and Chester O. McCorkle, Jr. "Trends in the U.S. Food-Processing Industry: Implications for Modeling and Policy Analysis in a Dynamic Interactive Environment." American Journal of Agricultural Economics 67.5 (1985): 1149-54.

Broomhall, David. The Economic Contribution of the Food and Agricultural System in Indiana. West Lafayette: Purdue University, 1996.

---. "Microcomputer-Based Input-Output Modeling: Applications to Economic Development." American Journal of Agricultural Economics 76.3 (1994): 682-83.

"C.P.I. Inflation Calculator". US Bureau of Labor Statistics 2009. $<$ www.bls.gov/data/inflation_calculator.htm $>$.

Deller, Steven C., N.R. Sumathi, and David Marcouiller. "Regional Economic Models for the State of Wisconsin: An Application of the Micro-Implan Modeling System." University of Wisconsin-Madison/Extension, 1993.

Goldman, George, and Aya Ogishi. The Economic Impact of Waste Disposal and Diversion in California. Berkley: University of California, Berkley, 2001.

Guo, Jiemin, Ann M. Lawson, and Mark A. Planting. "From Make-Use to Symmetric I-O Tables: An Assessment of Alternative Technology Assumptions." Ed. U.S. Department of Commerce: Bureau of Economic Analysis, 2002.

Haggblade, Steven, Jeffrey Hammer, and Peter Hazell. "Modeling Agricultural Growth Multipliers." American Journal of Agricultural Economics 73.2 (1991): 361-74.

Hall, T.Y., and R.K. Skaggs. "Economic Impact of Southern New Mexico Vegetable Production and Processing." New Mexico State University, 2003. 
Hamilton, Joel R., Norman K. Whittlesey, Henry M. Robinson, and John Ellis. "Economic Impacts, Value Added, and Benefits in Regional Project Analysis." American Journal of Agricultural Economics 73.2 (1991): 334-44.

Holland, David, and J.H. Yeo. "The Economic Impact of Potatoes in Washington State." Washington State University, 2001.

Lazarus, William. "Implan's Weakest Link: Production Functions or Regional Purchase Coefficients." Journal of Regional Analysis and Policy 32.1 (2002): 33-48.

Lazarus, William F., Diego E. Platas, George W. Morse, and Steffanie Guess-Murphy. "Evaluating the Economic Impacts of an Evolving Swine Industry: The Importance of Regional Size and Structure." Review of Agricultural Economics 24.2 (2002): 458-73.

Leones, Julie, Gerald Schluter, and George Goldman. "Redefining Agriculture in Interindustry Analysis." American Journal of Agricultural Economics 76.5 (1994): 1123-29.

McHargue, Jim. "Stanislaus County: Best Waste Prevention Program". Modesto, 2001. (November 1, 2007): California Integrated Waste Management Board. July 16, 2007. <http://www.ciwmb.ca.gov/>.

McNicoll, I. H., and R. G. Baird. "Empirical Applications of Regional Input-Output Analysis: A Case Study of Shetland." The Journal of the Operational Research Society 31.11 (1980): 983-91.

Mulkey, W. David, and Alan W. Hodges. "Using Implan to Assess Local Economic Impacts." Gainesville, FL: University of Florida, 2000.

"Municipal Solid Waste Generation, Recycling, and Disposal in the United States: Facts and Figures for 2006". 2006. U.S. Environmental Protection Agency.

<http://www.epa.gov/>.

Olson, Doug, and Scott Lindall. "Implan Pro User's Guide." 3rd ed. Stillwater, MN: Minnesota IMPLAN Group, Inc., 2004.

Raa, Thijs ten, Debesh Chakraborty, and J. Anthony Small. "An Alternative Treatment of Secondary Products in Input-Output Analysis." The Review of Economics and Statistics 66.1 (1984): 88-97.

Schlosser, Janet A. "An Examination of County-Level Labor Market Responses to Economic Growth in Kansas." Kansas State University, 2008.

"Sector 31: Manufacturing: Geographic Area Series, Industry Statistics for the States, Metropolitan and Micropolitan Statistical Areas, Counties and Places: 2002". 2007. U.S. Census Bureau. 2009. <http://factfinder.census.gov/>. 
Shields, Martin. "The Philosophy Underlying Community Policy Models." Community Policy Analysis Modeling. Eds. T.G. Johnson, D.M. Otto and S. C. Deller. Ames, IA: Blackwell Publishing, 2006. 57-84.

Shields, Martin, and Fern K. Willits. "The Growing Importance of the Environmental Horticulture Industry in the Agricultural Economy of the Northeastern United States." Agricultural and Resource Economics Review 32.2 (2003): 259-71.

Stanbra, Ryan. "History of California Solid Waste Law, 1985-1989". Sacramento, CA, 2007. California Legislation. (November 1, 2007): California Integrated Waste Management Board. February 19 2008. <http://www.ciwmb.ca.gov/>.

"Stanislaus County Food Processing by-Products Use Program". 2006. Ed. CRWQCB California Regional Water Quality Control Board. August 10, 2007. $<$ http://www.swrcb.ca.gov/>.

"State and County Quick Facts: California". 2008. Ed. U.S. Census Bureau. February 19 2008. <http://quickfacts.census.gov/>.

Steenage, A.E. "The Commodity Technology Revisited: Theoretical Basis and an Application to Error Location in the Make-Use Framework." Economic Modeling 7 (1990): 376-87.

Stephens, Larry N. "California's 2006 Statewide Diversion Rate Estimate". Sacramento, CA, 2006. (January 9, 2008): California Integrated Waste Management Board. February 19 2008. <http://www.ciwmb.ca.gov/>.

Summary of California County Agricultural Commissioners' Reports, 2004-2005. Sacramento, 2006.

Tanjuakio, Rodolfo V., Steven E. Hastings, and Peter J Tytys. "The Economic Contribution of Agriculture in Delaware." Agricultural and Resource Economics Review 25.1 (1996): 46-53.

Thompson, N., and L. Haskins. "Searching For "Sound Science": A Critique of Three University Studies on the Economic Impacts of Large-Scale Hog Operations." Walthill, NE: Center for Rural Affairs, 1998.

Tolbert, Mark. "Nation's Population to Reach 300 Million on Oct. 17." Ed. U.S. Department of Commerce: U.S. Census Bureau, 2006.

Treyz, George. Regional Economic Modeling. Boston, MA: Kluwer Academic Publishers, 1993. 
APPENDICES 


\section{APPENDIX A}

(Proprietor Name)

(Business Name)

(Business Address)

Dear (Proprietor),

My name is Sean Hurley with the Department of Agribusiness at the California

Polytechnic State University. I have been approached by the California Institute for the Study of Specialty Crops to assist in a study assessing the economic impact of Stanislaus canneries on the local economy. More specifically, the project examines what would happen to Stanislaus County if the Food Processing Byproduct Use Program was significantly altered. I am working in cooperation with Bill Lyons. I received your name from Denton Hoeh of the Stanislaus County Environmental Resources Department as a participant in this program. I believe you could provide us with valuable information to facilitate this research project.

In order to run our analysis, we are collecting information pertaining to your cannery operations. We need some specifics concerning your yearly revenue, your employment numbers and payroll expense, the percentage of your employees residing in the county, and alternative disposal options and costs. All this information will remain confidential and no names will be used in the report.

If you have any questions regarding this study, please feel free to contact me either by phone or email (listed below). Thank you for assisting in this research. Your cooperation is greatly appreciated.

Sincerely,

Sean Hurley

Department of Agribusiness

California Polytechnic State University

San Luis Obispo, CA 93407-0254

Ph: 805-756-5050

Email: shurley@calpoly.edu 